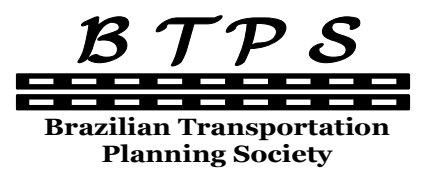

Planning Society
Journal of Transport Literature

Vol. 8, n. 4, pp. 109-145, Oct. 2014

Research Directory
JTL | RELIT

www.journal-of-transport-literature.org ISSN 2238-1031

\title{
Proposta metodológica para avaliação dos benefícios de um centro de distribuição urbano para mitigação dos problemas de logística urbana
}

[Proposed methodology to evaluate the benefits of an urban distribution center for mitigation of city logistics problems]

\author{
Leise Kelli de Oliveira*, Vagner de Assis Correia \\ Federal University of Minas Gerais - Brazil
}

Submitted 20 Mar 2013; received in revised form 23 Dec 2013; accepted 2 Mar 2014

\begin{abstract}
Resumo
Este trabalho apresenta uma metodologia desenvolvida para avaliar a implantação de um modelo de centros de distribuição de mercadorias em áreas urbanas (CDU) com critérios econômicos e ambientais. A metodologia é composta por quatro etapas: modelo de adesão (etapa 1), utilizando a técnica de preferência declarada, para a definição dos cenários de atendimento da demanda do sistema de entrega de produtos proposto para a cidade (etapa 2). Para cada um dos cenários, foram realizados estudos de localização de instalações e de roteirização de veículos (etapa 3) utilizando o software Transcad. Na etapa 4 foram feitas as avaliações econômica, ambiental e logística dos cenários analisados. A metodologia foi aplicada em Belo Horizonte (MG) e os resultados indicaram que o CDU reduziu o número de veículos de carga em circulação na cidade em até 51,4\%, além de aumentar a produtividade destes equipamentos com uma elevação de $264 \%$ no número de rotas alocadas por veículo e diminuir em $37,27 \%$ a emissão de poluentes e o consumo de combustíveis fósseis. Estes resultados apontam que o CDU pode aperfeiçoar os processos logísticos urbanos e mitigar as externalidades negativas do transporte de produtos nas cidades.
\end{abstract}

Palavras-Chave: logística urbana, distribuição urbana de mercadorias, centro de distribuição urbano.

\begin{abstract}
This paper presents a methodology to evaluate the implementation of urban distribution centers of products model (UDC) with economical and environmental criteria. The methodology is shared in four steps: adoption model (step 1), based on stated preference, in order to define scenarios to achieve the demand offered by the product delivery system to the city (step 2). To each scenario, it was performed facility location and routing studies (step 3) by using Transcad software. In step 4, it was made economical, environmental and logistic evaluations of each scenario analyzed. This methodology was applied in Belo Horizonte (MG) and showed that the UDC reduced the number of cargo vehicle to drive in the city by up 51.4\%, besides that, the model increased the productivity of these vehicles by elevating in $264 \%$ the routes numbers allocated in each truck and decreased in $37.27 \%$ the pollutant emission and the fossil fuel consumption. These results indicated that the UDC can improve urban logistics processes and it can mitigate negatives externalities of products transportations in cities.
\end{abstract}

Key words: city logistics, urban freight transport; urban distribution center.

*Email: leise@etg.ufmg.br.

\section{Recommended Citation}

Oliveira, L. K. and Correia, V. A. (2014) Proposta metodológica para avaliação dos benefícios de um centro de distribuição urbano para mitigação dos problemas de logística urbana. Journal of Transport Literature, vol. 8, n. 4, pp. 109-145.

- JTL/RELIT is a fully electronic, peer-reviewed, open access, international journal focused on emerging transport markets and published by BPTS - Brazilian Transport Planning Society. Website www.journal-of-transport-literature.org. ISSN 2238 -1031. 


\section{Introdução}

O transporte urbano de cargas é uma atividade fundamental para o desenvolvimento econômico das cidades. Contudo, efeitos adversos ao meio ambiente são observados, como o comprometimento das condições do tráfego de veículos, o elevado consumo energético e a emissão de poluentes (Castro, 2013). Uma das formas de mitigar os problemas da distribuição urbana de mercadorias é a implantação de um modelo de centros de distribuição urbanos de mercadorias (CDU). Para avaliar os benefícios da implantação de um CDU, este trabalho apresenta uma proposta metodológica composta por quatro etapas: modelo de adesão (etapa 1) que utilizou a técnica de preferência declarada para definir os cenários de adesão (etapa 2), que influenciam na localização e roteirização das entregas (etapa 3). Na etapa 4 foram realizadas as avaliações econômica, ambiental e logística dos resultados. Para a realização da etapa 3 foram utilizados os módulos de logística do software Transcad. A metodologia foi aplicada para Belo Horizonte (MG), obtendo resultados que indicam o potencial da solução analisada como alternativa para aperfeiçoar os processos logísticos urbanos e mitigar as externalidades negativas do transporte de cargas nas cidades.

Nos últimos anos, muitos estudos têm sido realizados no que se refere aos níveis de tráfego e seus impactos nas grandes cidades. Estes se concentram, essencialmente, na análise do transporte público e dos veículos particulares com uma preocupação relativamente pequena com o transporte urbano de cargas (Browne et al., 2005).

No Brasil, várias cidades têm promovido políticas com intuito de conter os efeitos negativos da distribuição de mercadorias nos centros urbanos, com estratégias visam, fundamentalmente, restringir o acesso de veículos de grande porte em áreas específicas. Contudo, Dablanc (2010) ressalta que as políticas restritivas em relação à entrada de veículos de carga nos centros urbanos baseadas na capacidade ou tamanho nem sempre são interessantes, uma vez que promovem o uso de equipamentos de menor capacidade, que podem contribuir para o aumento dos congestionamentos e a diminuição da eficiência do sistema transporte de mercadorias, que pode aumentar os custos das empresas. Assim, é fundamental identificar alternativas que possam contribuir para uma racionalização do uso das estruturas viárias existentes de modo a diminuir os congestionamentos e, consequentemente, mitigar as externalidades negativas do 
transporte de cargas no ambiente urbano e organizar os processos logísticos nas cidades.

É neste contexto que se insere o conceito de CDU, definido por Browne et al. (2005) como uma “instalação logística, situada relativamente próxima a área urbana, em que as entregas são consolidadas e realizadas dentro desta área". Este trabalho apresenta uma metodologia para a avaliação econômica e ambiental da implantação de um CDU. Esta metodologia foi desenvolvida, sobretudo, com base nos trabalhos de Browne et al. (2005), Crainic et al. (2004), Carrara (2007) e Quak (2008). Os primeiros autores definiram o conceito de CDU e realizaram uma ampla pesquisa elencando fatores de sucesso e fracasso em diversas aplicações deste sistema de distribuição. Já Crainic et al. (2004) desenvolveram um modelo de distribuição de mercadoria em dois níveis com a introdução de um elo intermediário de instalações para o transbordo de mercadorias de caminhões com maiores dimensões para veículos urbanos de carga. Carrara (2007) utilizou o software Transcad para um estudo de localização de instalações e roteirização de veículos para a implantação de um centro de distribuição de cargas na cidade de Uberlândia. Quak (2008) analisou os impactos ambientais da movimentação de cargas no ambiente urbano.

Browne et al. (2005) relatam ser poucos os estudos que avaliam os benefícios da implantação do CDU. Além disto, os autores apontam que não foi feito um estudo dos impactos econômicos e ambientais dos casos analisados na pesquisa realizada. Neste contexto, este trabalho apresenta uma proposta metodológica para a avaliação da implementação do CDU, analisando diferentes cenários de adesão de transportadores e varejistas e buscando identificar seus impactos com base em parâmetros econômicos e ambientais desenvolvidos.

A abordagem desenvolvida por Crainic et al. (2004) se fundamenta em um problema de otimização cujo objetivo é minimizar os custos totais de transporte de produtos por meio da roteirização de veículos e a escolha da localização de pontos de transbordo situados em uma camada intermediária, ou seja, entre os varejistas e os centros de distribuição das empresas. Perboli et al. (2011), Santos et al. (2012), Baldacci et al. (2013) e Jepsen et al. (2013), assim como Crainic et al. (2004), trabalharam com o este problema com intuito de desenvolver algoritmos para a sua solução utilizando, sobretudo, técnicas de otimização exata. Estes autores obtiveram resultados ótimos nos procedimentos de busca utilizados em seus algoritmos para instâncias de testes que chegaram a, aproximadamente, 200 varejistas. 
Contudo, apesar da confiabilidade dos resultados, os estudos realizados por Perboli et al. (2011), Santos et al. (2012), Baldacci et al. (2013), Jepsen et al. (2013) e Crainic (2004) não são capazes de avaliar situações reais e complexas como, por exemplo, as de uma cidade onde existem milhares de varejistas, diversos depósitos de empresas e vários locais candidatos a instalações logísticas de transbordo de cargas que devem ser escolhidos em um estudo de localização de um modelo de CDU. Além disto, os modelos de otimização utilizados nestes trabalhos não abordam os impactos ambientais das soluções ótimas apontadas por seus algoritmos. Nesse sentido, este trabalho apresenta uma forma sistematizada de avaliar os impactos econômicos e ambientais de um CDU que pode ser aplicada em problemas de grandes dimensões como, por exemplo, uma extensa região urbana. Além disto, a metodologia desenvolvida neste trabalho foi utilizada em um ambiente de testes que aproximou-se da realidade de grandes conglomerações urbanas na medida em que as informações que serviram de base para o estudo originaram-se da região metropolitana de Belo Horizonte.

Carrara (2007) realizou um estudo de localização e roteirização de veículos utilizando o Transcad para a instalação de um centro de distribuição urbano de cargas na cidade de Uberlândia. Neste sentido, a autora trabalhou com um modelo de distribuição de carga com uma camada, ou seja, as mercadorias partem do CDU diretamente para os varejistas situados na região urbana congestionada visando minimizar os custos de transporte. O estudo desenvolvido neste artigo apresenta um modelo de CDU com duas camadas de distribuição, conforme conceito apresentado por Crainic et al. (2004), que, segundo Dablanc (2007), mostrou-se mais adequado às cidades com grande fluxo de veículos e que possuem restrições à movimentação de veículos de carga. Além disto, este trabalho apresenta uma metodologia para análise da adesão dos varejistas fundamentada em um modelo de preferência declarada desenvolvido por Martins (2005), aspecto importante para a implementação de um CDU, mas ainda pouco abordado pela literatura, segundo Rooijen e Quak (2010).

Quak (2008) realizou uma pesquisa em que foram discriminados os impactos econômicos, sociais e ambientais da distribuição de cargas sobre as cidades. Este trabalho estabelece critérios específicos para a avaliação econômica e ambiental do CDU com base nos aspectos levantados por Quak (2008).

Os resultados obtidos da aplicação da metodologia indicaram que a implantação de um CDU reduz significativamente as externalidades do transporte urbano de cargas, produzindo um 
ambiento urbano mais seguro, com uma economia mais eficiente, conforme indicado por Quak (2008). O autor relata ainda que o CDU está entre as iniciativas de logística urbana que visam melhorar a sustentabilidade das cidades pela mudança da infraestrutura física utilizada pelo transporte urbano de cargas. Isto porque esta iniciativa oferece uma oportunidade para a consolidação de cargas que se destinam a áreas urbanas podendo assim diminuir os impactos negativos da distribuição de produtos como a poluição do ar e o consumo de combustíveis além de reduzir o número de veículos em circulação em regiões congestionadas.

Para apresentar a metodologia e os resultados provenientes de sua aplicação, este artigo está assim subdividido: Após esta introdução, a Seção 2 apresenta o conceito e os benefícios da implantação de um CDU, a Seção 3 apresenta a metodologia proposta para avaliar os benefícios da implantação desta solução e na Seção 4 são apresentados os resultados da aplicação da metodologia para Belo Horizonte (MG). Por fim, são apresentadas as considerações finais desta pesquisa.

\section{Centro de distribuição urbano}

Esta primeira seção apresenta os conceitos e benefícios da solução de logística urbana investigada neste artigo. A consolidação de cargas de diferentes embarcadores e transportadoras em um mesmo veículo, associada à coordenação de operações nas cidades é vista como uma das mais importantes formas de mitigação das externalidades causadas pelo transporte de mercadorias nos centros urbanos (Benjelloun et al., 2009; Karrer e Ruesch, 2007; Crainic et al., 2009a; Crainic et al., 2009b; Browne et al., 2007; Nemoto et al., 2006). Neste sentido, o conceito de CDU é considerado um instrumento importante dentre as iniciativas da Logística Urbana (Crainic et. al., 2009a).

De maneira geral, as cadeias de suprimentos otimizam suas entregas tendo em vista a origem do fluxo, por exemplo, um centro de distribuição varejista, enquanto que, para a cidade, a otimização a partir do destino poderia alcançar melhores resultados. Neste sentido, do ponto de vista da cidade, a realização de roteiros tratando as regiões congestionadas como ambientes fechados pode, por exemplo, contribuir para a redução dos veículos nas áreas com maiores problemas em relação ao trânsito. É importante mencionar que o aumento das regulamentações sobre a distribuição urbana, como as restrições de acesso de veículos (capacidade e/ou 
tamanho), janela de tempo e as zonas ambientais, vem pressionando a eficiência das cadeias de suprimentos (Rooijen e Quak, 2010).

Quak (2008) destaca que os CDU's estão entre as iniciativas de Logística Urbana, que visam melhorar a sustentabilidade das cidades pela mudança da infraestrutura física utilizada pelo transporte urbano de cargas. Segundo o autor, o conceito de CDU não é um novo, uma vez que ele já foi estudado na década de 1970. McDermott (1975) apud Quak (2008) analisou os potenciais benefícios e desvantagens da operação de terminais de consolidação urbana para os transportadores, embarcadores, consumidores, sociedade e administradores públicos.

Segundo Karrer e Ruesch (2007), os CDU's foram desenvolvidos, inicialmente, no Reino Unido e mais tarde na Holanda e Mônaco, fazendo parte da política nacional de muitos países europeus. Esse conceito foi um tópico proeminente na década de 1990 em relação às atividades da Logística Urbana, com destaque para a Itália que, no ano de 1990, foi o primeiro país a estabelecer uma estratégia nacional de CDU, sendo seguida pela Alemanha, em 1992, e pela França, em 1993. Apesar do elevado interesse nos CDU's, evidenciado pelas numerosas pesquisas realizadas na década de 1990, destaca-se que houve poucos modelos implementados, sendo que muitos destes tiveram suas operações encerradas em virtude do baixo volume movimentado e de insatisfação com os níveis de serviço apresentados. Browne et al.(2005) ressaltam que, dos 200 modelos de CDU planejados ou executados na Alemanha, apenas cinco continuam operando.

Com efeito, a partir do século XXI, verifica-se outro período de interesse em relação aos CDU's, onde se destacam, por exemplo, as iniciativas implementadas ou pesquisadas em: La Rochele (Partier, 2006 apud Quak, 2008), Berlin (Hesse, 2004 apud Quak, 2008), Roma (Crainic et al., 2004), Lyon (Ambrosini, 2004 apud Quak, 2008), Siena (Valentini et al., 2001 apud Quak, 2008), Nijmegen (Rooijen e Quak, 2010), Bristol (Minihane, 2009), e Westpomeranian Region (Chwesiuk et al., 2010).

Atualmente, o interesse pelos CDU é bastante heterogêneo entre os países europeus, uma vez que alguns ainda permanecem céticos em relação aos potenciais benefícios que esta alternativa pode trazer, e outros esperam um segundo período de implementações bem sucedidas, tendo em vista o aprendizado com as falhas do passado. Todavia, ressalta-se que o crescimento da preocupação ambiental em relação às externalidades oriundas do transporte aumentará a 
necessidade de ações para mitigação destes problemas, elevando as discussões acerca das possíveis soluções, incluindo os CDU (Karrer e Ruesch, 2007).

Dablanc (2007) salienta que muitos projetos envolvendo a instalação de um único CDU não tiveram sucesso em grandes cidades com alta densidade populacional e elevada concentração de atividades comerciais, administrativas e culturais. Crainic et al. (2009a) ressaltam que, nestas cidades, geralmente, os veículos que possuem permissão para realizar as entregas, ou seja, que atendem às restrições de peso e tamanho, viajam longas distâncias até os pontos onde estão localizados os clientes. Com efeito, estes veículos não são apropriados para viagens longas e, por outro lado, o tipo de equipamento adequado para viagens mais extensas não possui permissão para a realização das entregas nos centros urbanos em virtude de seu tamanho e/ou capacidade de carga.

Diante desta situação, Crainic et al. (2004) expandem o conceito de CDU único para CDU múltiplo como forma de mitigar os problemas de adequação de frota para operação nas grandes cidades. Neste conceito, o sistema de distribuição de cargas é dividido em dois níveis: CDU's e satélites. Os CDU's são localizados fora da área urbana e recebem a carga que será distribuída nos centros urbanos. Já os satélites são alocados em áreas próximas de sua região de cobertura, na área urbana, e recebem a carga dos CDU's para entrega nos clientes. Neste sistema, estão envolvidos dois tipos de veículos, veículos com maior capacidade de carga, que transferem a carga do CDU's para os satélites, e veículos ambientalmente amigáveis, que realizam as entregas para os clientes a partir dos satélites.

Browne et al. (2005) identificaram vantagens e desvantagens em relação à implantação do CDU. Entre as vantagens destacam-se os benefícios sociais e ambientais como operações de transporte na área urbana com menor emissão de poluentes, a melhoria no planejamento e operações logísticas além do potencial de ligação com outras políticas de mobilidade urbana. No que se refere às desvantagens os autores citam o potencial aumento de custos e a existência de apenas um CDU pode trazer dificuldades na realização de toda a movimentação de produtos tendo em vista as varrições no tipo e exigências de manuseio e estocagem.

Em relação aos impactos sobre as operações de transporte, Browne et al. (2005) salientam que, apesar de se apresentar como uma das principais justificativas para a implementação de um $\mathrm{CDU}$, existe na literatura poucos estudos que visam identificar tais impactos. No entanto, em 
termos gerais, o uso de um CDU pode resultar em benefícios substanciais para o transporte, dependendo do nível de absorção e da natureza deste modelo. Os principais benefícios incluem a redução no número de viagens e da distância percorrida pelos veículos de carga, a melhoria nas taxas de utilização do veículo (peso/volume) nas entregas realizadas pelo CDU e, consequentemente, redução no custo de transporte unitário nas entregas ao consumidor final, a redução da quantidade de veículos presentes na área atendida pelo CDU e oportunidade para melhoria do faturamento com cargas de retorno.

Browne et al. (2007) salientam que a avaliação de CDU's é uma tarefa complexa na medida em que ele pode ter um ou múltiplos objetivos e, desta forma, existem várias abordagens visando avaliar as aplicações e os tipos de CDU. Com efeito, algumas medidas são tipicamente utilizadas como forma de avaliar os modelos propostos, entre estas, destacam-se: o número de rotas realizadas dos centros de distribuição até os seus clientes, distância percorrida pelos veículos envolvidos neste modelo, número de veículos, tempo total de realização das rotas, número de produtos entregues por ponto de destino, quantidade de carga por veículo, frequência e tempo de estacionamento nas vagas destinadas à carga e descarga na cidade, consumo de combustível e emissão de poluentes dos veículos envolvidos no CDU e, por último, custos operacionais.

\section{Metodologia proposta}

Esta seção apresenta a metodologia proposta, que tem o intuito de avaliar os benefícios da implantação de um centro de distribuição urbano de mercadorias apresentada, esquematicamente, na Figura 1. Ela foi desenvolvida em quatro etapas: i. modelo de adesão, ii. proposição de cenários para análise, iii. modelo de otimização para cada cenário definido e iv. avaliação econômica, ambiental e logística dos resultados. Segundo Browne et al. (2007), os métodos propostos para avaliação dos benefícios de um CDU preocupam-se em melhorar a ocupação dos veículos, calculado na etapa iii desta metodologia. Contudo, Karrer e Ruesch (2007) indicam como um dos fatores de fracasso desta iniciativa a relutância dos varejistas em aceitar novos modelos de distribuição e o medo da perda da competitividade e do contato com os consumidores por parte dos transportadores. Considerando isto, esta metodologia foi desenvolvida para analisar até que nível de adesão de varejistas seria possível obter os benefícios de um centro de distribuição urbano, reduzindo assim, as externalidades da 
distribuição urbana de mercadorias. Assim, este trabalho contribui com a avaliação da demanda através do modelo de adesão, utilizando para isto, a técnica de preferência declarada.

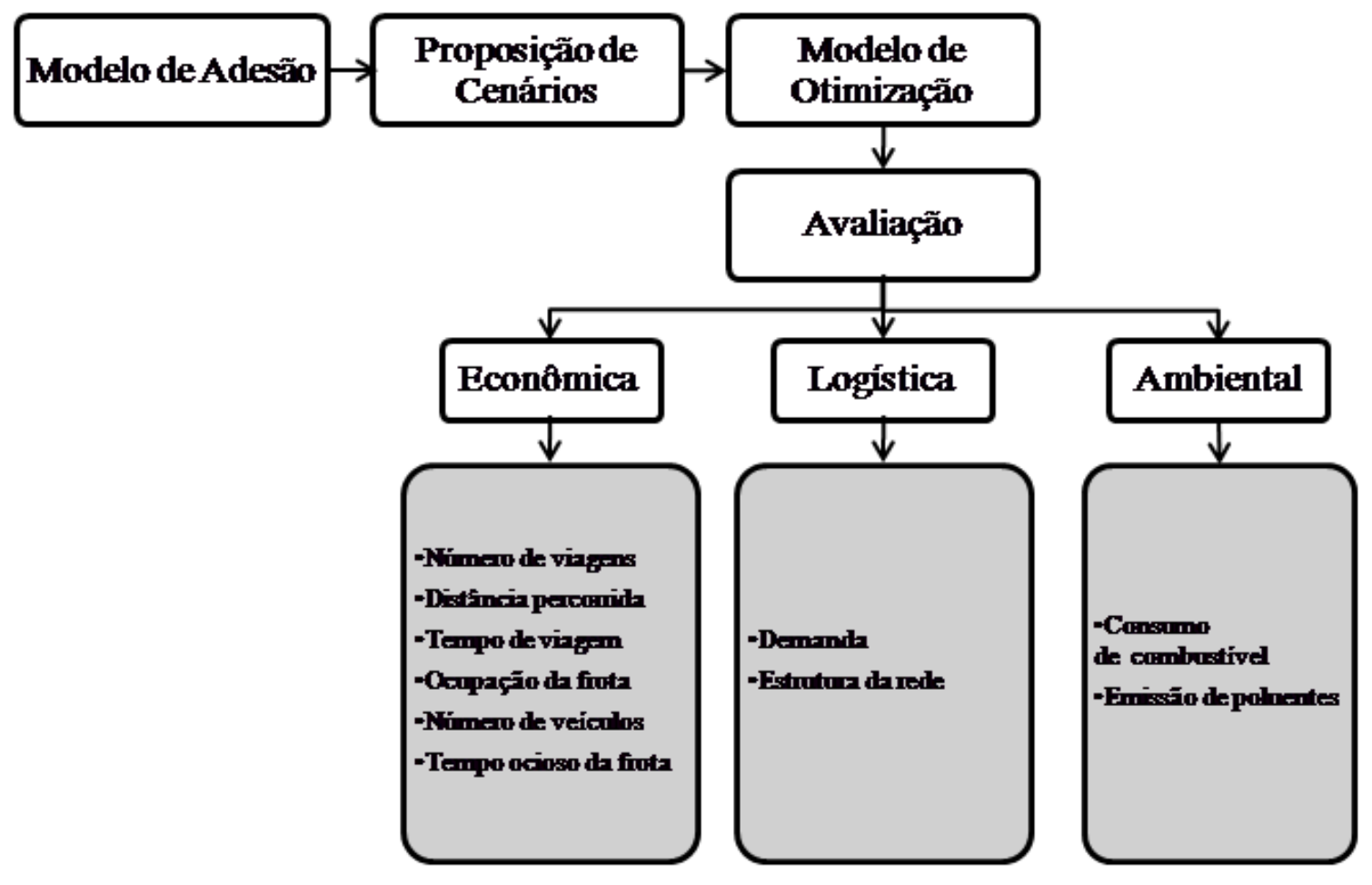

Figura 1 - Estrutura da metodologia ${ }^{1}$

É importante mencionar que a metodologia proposta neste trabalho adota o conceito de sistema de distribuição em duas camadas, proposto por Crainic et al. (2009b), em que foi expandido o CDU único para CDU múltiplo como forma de mitigar os problemas de adequação de frota para operação nas grandes cidades. Neste conceito, o sistema de distribuição de cargas é dividido em dois níveis: CDU e terminais de apoio. Os CDU's são localizados fora da área urbana e recebem a mercadoria que será distribuída nos centros urbanos. Já os terminais de apoio são alocados em áreas próximas de sua região de cobertura e recebem a carga dos CDU's para a entrega nos clientes.

Neste sistema, estão envolvidos dois tipos de veículos, caminhões com maior capacidade de carga, que transferem a carga do CDU para os terminais de apoio e veículos ambientalmente amigáveis, como os elétricos ou os Veículos Urbanos de Carga (VUC's), que realizam as entregas para os clientes a partir dos terminais de apoio. As Figuras 2 e 3 apresentam, respectivamente, os conceitos de CDU único e CDU múltiplo abordados neste trabalho.

\footnotetext{
${ }^{1}$ Fonte: autores (elaboração própria).
} 


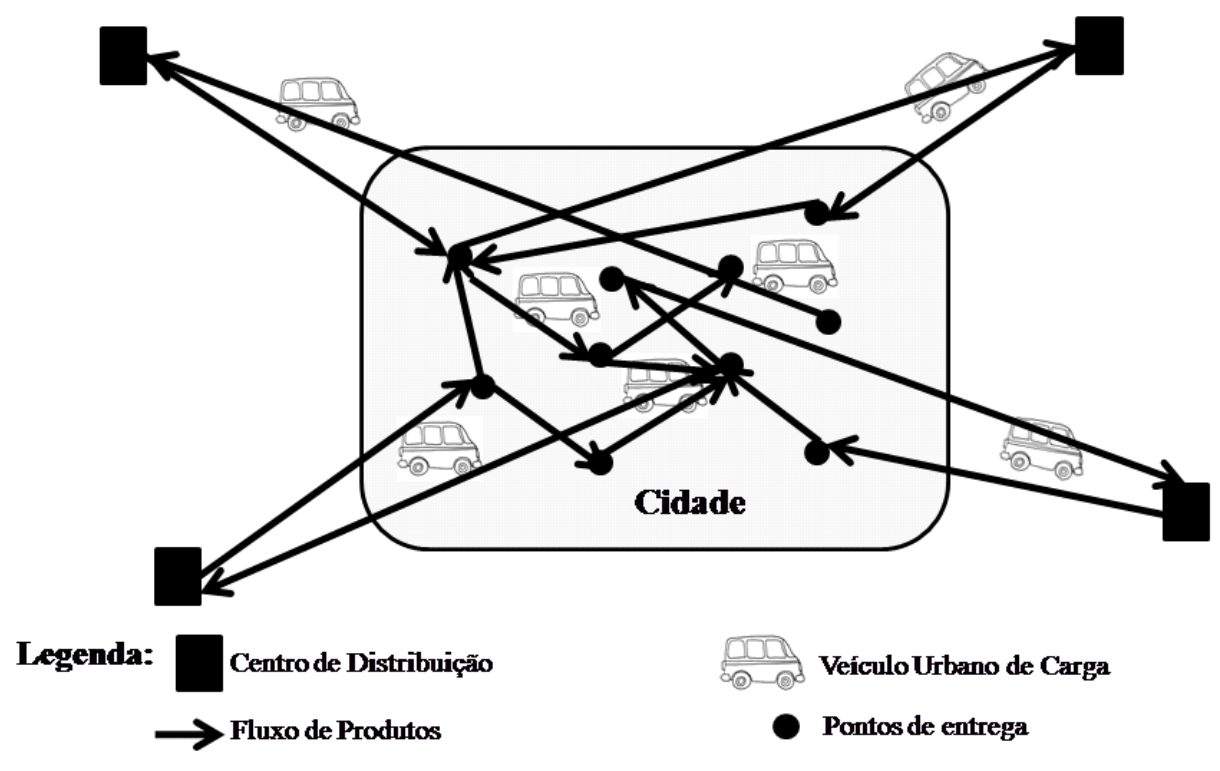

Figura 2 - Conceito CDU único²

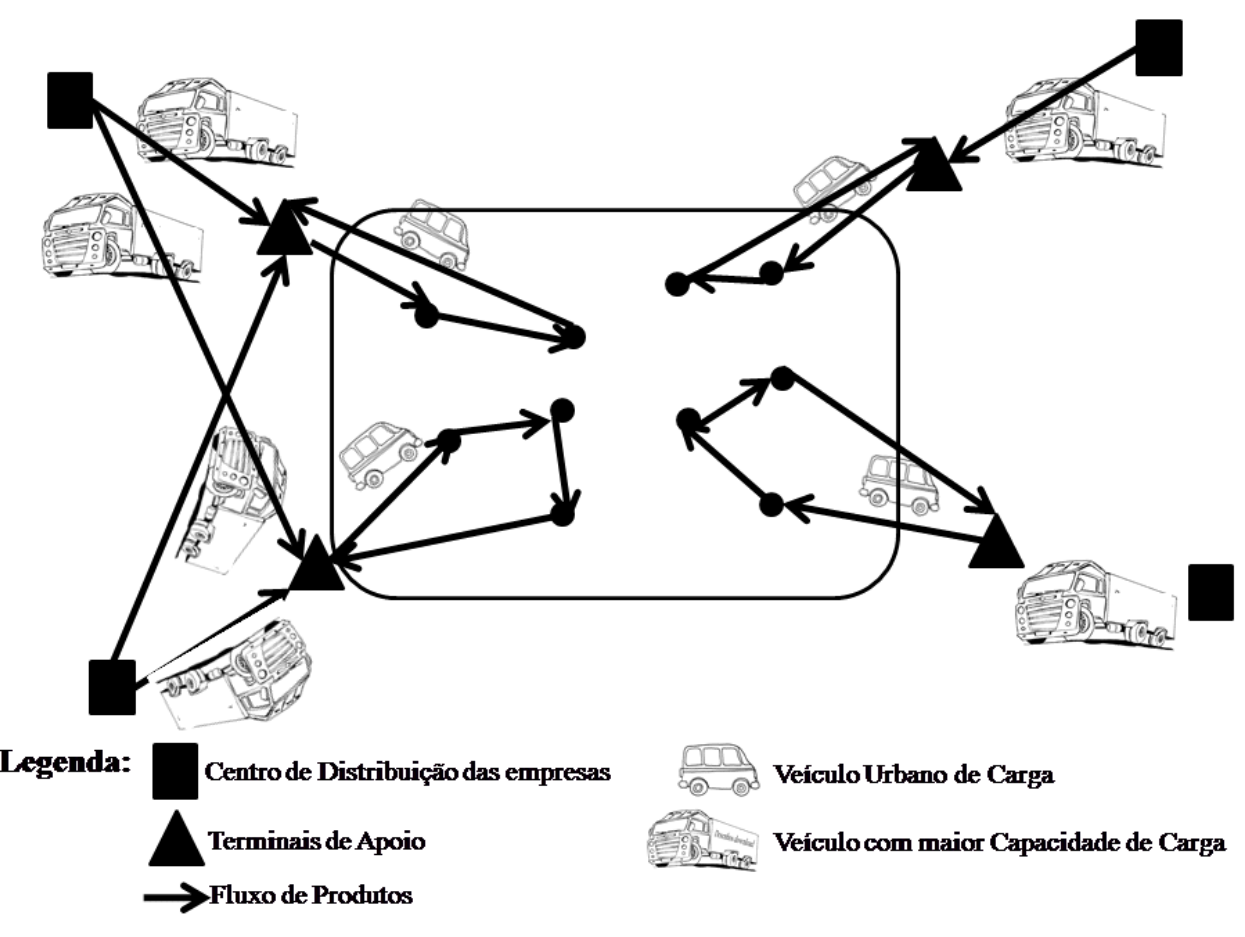

Figura 3 - Conceito CDU múltiplo ${ }^{3}$

\footnotetext{
${ }^{2}$ Fonte: autores (elaboração própria).

${ }^{3}$ Fonte: autores (elaboração própria).
} 
A seguir serão detalhadas cada uma das etapas que compõem a metodologia proposta neste trabalho.

\subsection{Modelo de Adesão}

O modelo de adesão tem como objetivo avaliar a adesão de transportadores e varejistas ao centro de distribuição urbana de mercadorias e, esta avaliação é fundamental, pois, conforme salientam Rooijen e Quak (2010), um dos principais fatores de insucesso das experiências com CDU em algumas cidades européias decorreu da inexistência de uma análise prévia da demanda potencial dos varejistas em relação a este esquema.

Uma maneira de avaliar os principais elementos de uma adesão é através de técnica de preferência declarada (PD), que identifica os fatores relevantes num processo de decisão. Segundo Almeida (1999), a manifestação das preferências dos indivíduos em relação a um serviço reflete o seu comportamento frente a um conjunto de opções disponíveis. Esta técnica envolve as preferências dos indivíduos e estima o seu comportamento através de modelos de escolha (Kroes e Sheldon, 1988), permitindo analisar situações ainda não existentes, e identificar características do sistema em estudo que sejam relevantes para o usuário. Possibilita, ainda, explorar as combinações dos atributos e sua variabilidade, uma vez que revela a importância relativa de cada atributo selecionado, tornando possível configurar situações bem próximas dos interesses dos usuários.

Para se desenvolver o modelo de adesão utilizando a técnica de preferência declarada é necessário definir atributos ao modelo. Entende-se por atributos, as principais características do sistema atual com impacto direto na adoção do sistema proposto. Após a avaliação dos potenciais custos e benefícios para os transportadores, identificaram-se os mais relevantes tendo considerando a realidade brasileira, definindo-se, assim, os seguintes atributos para o modelo: 
- Ocupação do Veículo: quantidade de carga (peso e/ou volume) transportada por veículo. Supõe-se que o CDU melhore os níveis de ocupação de carga dos veículos;

- Estacionamento: local para as operações de carga e descarga no centro urbano. Supõe-se que a potencial redução do número veículos de carga nos centros urbanos com o CDU pode melhorar as condições de estacionamento;

- Parceria: prestação do serviço em cooperação com outras empresas transportadoras. Supõe-se que o CDU exija o compartilhamento de cargas entre os transportadores;

- Investimento: alocação de recursos em novas tecnologias para distribuição de carga no centro urbano. Uma das consequências do CDU é a necessidade de investimentos em novas tecnologias como o GPS (Global Positioning System) e em veículos urbanos de carga menos poluentes.

De forma análoga, para os varejistas, foram identificados os seguintes atributos:

- Custo: dispêndio financeiro dos varejistas para o alcance de seus objetivos. Supõe-se que uma das consequências do CDU seja o aumento nos custos em virtude do acréscimo de mais um estágio na cadeia de suprimentos;

- Prestação de Serviço: forma com que os varejistas são atendidos por seus fornecedores. Supõe-se que o CDU proporcione a melhoria dos serviços prestados através de maior flexibilidade operacional como, por exemplo, a possibilidade de fracionamento do pedido realizado e redução do número de entregas;

- Confiabilidade: credibilidade dos varejistas em relação aos serviços prestados pelas transportadoras. Supõe-se que o CDU melhore a confiabilidade do serviço com, por exemplo, o aprimoramento na pontualidade das entregas;

- Estoque versus Exposição: quantidade de produtos armazenados em contra posição com a quantidade de produtos expostos. Supõe-se que o CDU proporcione o aumento do espaço de exposição de produtos por meio da redução das áreas de armazenagem.

Para cada atributo considerado no estudo, foram definidos dois níveis de escolha: o primeiro nível corresponde à situação atual e o segundo nível considera as consequências da implantação do CDU. A Tabela 1 e 2 apresentam os atributos e a descrição dos respectivos níveis considerados na avaliação dos transportadores e varejistas, respectivamente. 
Tabela 1 - Atributos e níveis para avaliar adesão de transportadores

\begin{tabular}{ll}
\hline \multicolumn{1}{c}{ Atributo } & \multicolumn{1}{c}{ Nível } \\
\hline \multirow{2}{*}{ Ocupação do Veículo } & 0: Situação Atual \\
& 1: Melhoria nos níveis de ocupação do veículo \\
\hline \multirow{2}{*}{ Estacionamento } & 0: Situação Atual \\
& $\begin{array}{l}\text { 1: Facilidade para encontrar local para estacionar o veículo } \\
\text { para carga e descarga }\end{array}$ \\
\hline \multirow{2}{*}{ Parcerias } & $\begin{array}{l}\text { 0: Situação Atual } \\
\text { 1: Parcerias com outras empresas para melhorar os níveis de } \\
\text { consolidação de carga }\end{array}$ \\
\hline \multirow{2}{*}{ Investimento } & 0: Situação Atual \\
& 1: Necessidade de investir em novas tecnologias \\
\hline
\end{tabular}

Tabela 2 - Atributos e níveis para avaliar adesão de varejistas

\begin{tabular}{|c|c|}
\hline Atributo & Nível \\
\hline Prestação de Serviços & $\begin{array}{l}\text { 0: Situação Atual } \\
\text { 1: Potencial aumento de custos } \\
\text { 0: Situação Atual } \\
\text { 1: Melhoria da prestação do serviço }\end{array}$ \\
\hline $\begin{array}{lr}\text { Confiabilidade } & \text { no } \\
\text { Serviço } & \\
\text { Estoque } & \text { versus } \\
\text { Exposição } & \end{array}$ & $\begin{array}{l}\text { 0: Situação Atual } \\
\text { 1: Melhoria da confiabilidade do serviço de transporte } \\
\text { 0: Situação Atual } \\
\text { 1: Diminuição dos estoques e aumento do espaço de } \\
\text { exposição }\end{array}$ \\
\hline
\end{tabular}

Após a definição dos atributos e níveis, as alternativas seriam apresentadas aos entrevistados sob a forma de cartões, que foram confeccionados seguindo arranjos fatoriais, sendo utilizado o ensaio 1.1 , de fatorial $2^{4}$, com blocos balanceados com quatro alternativas, desenvolvido por Souza (1999). Com os cartões confeccionados, definiu-se que as pesquisas seriam realizadas pessoalmente, para capturar outros aspectos importantes e/ou perspectivas de rejeição ou adoção ao CDU. Neste sentido, foi elaborado um roteiro de entrevista específico para cada grupo entrevistado abordando questões referentes às características operacionais das empresas na região urbana pesquisada. Em relação aos varejistas verificou-se a frequência, número de entregas, volume, além da origem e tipo dos produtos recebidos. No que se refere aos transportadores buscou-se informações a respeito das condições de estacionamento para as operações de carga e descarga de produtos, o número e volume médio das entregas realizadas e o tipo e origem dos produtos transportados. 
Após a aplicação do roteiro de entrevistas foram apresentados os cartões para ordenação da preferência por meio de ranking, sendo a forma de aquisição das preferências mais utilizada, uma vez que é menos cansativa para o entrevistado (Almeida, 1999; Martins et al., 2005). Os dados foram processados utilizando o software LMPC (Logit Multinomial com Probabilidade Condicional) desenvolvido por Souza (1999). Além destes cálculos, o software realiza o teste das hipóteses nulas de todos os atributos para verificar a aderência dos resultados e utiliza o método da verossimilhança para obtenção das alternativas dos parâmetros e calibração do modelo.

Os resultados do modelo de adesão, que serão apresentados posteriormente, forneceram elementos para a elaboração e análise de cenários, sendo uma técnica bastante empregada na descrição e no estudo de planejamento e controle de diversos sistemas, essencial no processo de avaliação de um esquema de centro de distribuição urbano de mercadorias. Ressalta-se que foram avaliados cenários com variações na rede logística e no número de varejistas atendidos com intuito de identificar as vantagens da implantação do CDU. A variação na rede logística de atendimento visa analisar o impacto da disponibilidade e do custo imobiliário que possam ser utilizados nas operações que envolvem o CDU. Já a variação no número de varejistas identifica os resultados deste esquema tendo em vista o nível de adesão dos potenciais clientes.

\subsection{Proposição de cenários}

O primeiro passo na proposição dos cenários é a identificação de um panorama base que reflita as características correntes da distribuição urbana na cidade. Assim, pode-se avaliar os benefícios do CDU sobre a área analisada, considerando as várias configurações que ele pode assumir e compará-las a situação atual do processo logístico na cidade. Após a definição do cenário base, podem ser delineadas potenciais configurações para a rede logística de abastecimento da cidade.

\subsection{Modelo de otimização}

Esta etapa contempla a escolha da localização dos centros de distribuição e dos terminais de apoio e a roteirização de veículos para os dois níveis de atendimento, isto é, dos centros de distribuição aos terminais de apoio e, destes últimos, aos varejistas, seguindo as características de cada cenário proposto na etapa anterior. 
Vale destacar que esta etapa pode ser realizada de diversas formas, dependendo dos recursos disponíveis e a estrutura da região analisada. Neste sentido, uma alternativa possível é o desenvolvimento de um modelo matemático de otimização para a definição da localização dos terminais de apoio e do roteamento dos veículos. Outro caminho viável é a utilização de um software comercial, que possua, em suas rotinas, heurísticas para a determinação da localização das instalações logísticas e para a roteirização dos veículos. Neste trabalho optou-se pela utilização do TRANSCAD, software que atende aos quesitos mencionados.

Destaca-se que o problema de localização e roteirização em duas camadas é um tipo de problema difícil de ser resolvido de forma exata em um tempo polinomial com instâncias maiores. Santos et al. (2012), por exemplo, propuseram um algoritmo exato com resultados inéditos na literatura para instâncias com cerca de cinquenta clientes e cinco terminais de apoio. Desta forma, no contexto da metodologia proposta neste trabalho, é interessante aplicar os métodos heurísticos, como os contidos no TRANSCAD ou em outro pacote comercial, mesmo que os resultados oferecidos por eles não tenham a mesma qualidade dos métodos exatos. Isto porque as heurísticas oferecem a possibilidade de trabalhar com dados mais próximos da realidade dos grandes centros urbanos.

\subsection{Avaliação logística}

Um dos principais objetivos da logística urbana, segundo Crainic et al. (2009a), é a otimização da movimentação de carga tendo em vista a redução dos congestionamentos e o aumento da mobilidade nas cidades, a diminuição da emissão de poluentes e ruídos e a melhoria das condições de vida dos habitantes, evitando penalizar as atividades do centro urbano. Sendo assim, a avaliação logística é substancial para os estudos de CDU, uma vez que muitos esquemas, como em algumas experiências na França e Alemanha, não obtiveram resultados satisfatórios, em virtude, por exemplo, dos baixos índices de redução de emissão de poluentes, da necessidade contínua de subsídios públicos e do uso de uma frota inadequada. A avaliação prévia dos impactos de um CDU configura-se como etapa essencial para verificar a viabilidade de sua implantação. A avaliação logística é composta por três etapas de análise: econômica, ambiental e da rede de abastecimento. Estas etapas serão mostradas a seguir. 
Em relação às medidas da avaliação econômica, foi analisado o número de viagens realizadas pelos veículos, a distância percorrida, o tempo de viagem, a ocupação e o tempo ocioso da frota, além do número de veículos utilizados. Estes atributos são importantes elementos do custo de total de distribuição na cadeia de suprimentos e constituem-se como variáveis que impactam o trânsito da cidade.

Na avaliação ambiental foi quantificado o consumo total de combustíveis fósseis e a emissão de poluentes oriundos dos veículos utilizados nos modelos propostos. Estes aspectos contribuem para verificar a influência da estrutura logística de atendimento do centro de distribuição urbano sobre a qualidade do ar da cidade e a melhoria das condições de vida da população. Esta avaliação foi realizada por meio da ferramenta GHG Protocol que se constitui em uma metodologia para o cálculo da emissão direta de dióxido de carbono $\left(\mathrm{CO}_{2}\right)(\mathrm{GHG}$ Protocol, 2010).

A análise da rede de abastecimento visa estabelecer o comportamento dos impactos econômicos e ambientais em virtude da variação da quantidade de terminais logísticos e da adesão dos varejistas ao CDU. Este pode ser um importante aspecto para os tomadores de decisão visto que nem sempre é possível executar a alternativa mais favorável no que se refere à mitigação das externalidades negativas do transporte e redução dos custos logísticos. No entanto, é fundamental identificar os impactos das decisões sobre os quesitos avaliados para diminuir os riscos de insucesso da implantação de um CDU.

\section{Aplicação da metodologia e resultados}

A metodologia proposta neste trabalho foi aplicada para o município de Belo Horizonte, capital do Estado de Minas Gerais, com 2,4 milhões de habitantes e uma área de $331 \mathrm{~km}^{2}$. Belo Horizonte é o principal município de uma região metropolitana composto por 34 cidades e, aproximadamente, cinco milhões de habitantes (PBH, 2012). A partir de outubro de 2009, a prefeitura implantou regras para a circulação e operação dos veículos de carga na área central da cidade, impondo restrições à circulação de veículos acima de cinco toneladas e comprimento total superior a 6,5 metros em determinados dias e horários da semana. 


\subsection{Modelo de adesão}

Através dos resultados apresentados na Tabela 3, verifica-se que o custo é um atributo com uma importância significativa considerando o seu elevado valor no coeficiente da função utilidade $(-1,1319)$. Ressalta-se que este atributo se apresenta como uma inclinação contrária ao esquema de CDU em virtude do sinal negativo no coeficiente da função utilidade. $O$ atributo confiabilidade teve a segunda maior importância para os entrevistados com 0,8054, seguido pelo estoque versus exposição com 0,5254 e a prestação de serviço com 0,2013. Destaca-se que o teste $\mathrm{t}$ dos parâmetros avaliados indicou que a prestação de serviço não é um atributo significativo para o modelo, podendo ser considerado sem importância pelos varejistas entrevistados quando combinado com os demais uma vez que seu resultado $(1,3398)$ é rejeitado. Este fato pode ser reflexo de uma situação em que os varejistas creditam um elevado nível de satisfação em relação à atual prestação de serviços de seus fornecedores, sendo assim os ganhos adicionais provenientes da utilização do CDU podem não ser relevantes. Os resultados demonstraram que a adesão ao esquema de CDU do ponto de vista dos varejistas é condicionada, essencialmente, pelos custos adicionais potenciais, pela melhoria da confiabilidade do serviço dos transportadores e pelo aumento do espaço para a exposição de produtos em seus pontos de venda.

Tabela 3 - Resultados em relação aos transportadores

\begin{tabular}{lcccc}
\hline \multicolumn{1}{c}{ Atributo } & Coeficiente & Desvio-padrão & Teste T & IC (t=2,5\%) \\
\hline Custo & $-1,1319$ & 0,1620 & $-6,9853$ & {$[-1,456 ;-0,808]$} \\
\hline Prestação de Serviços & 0,2013 & 0,1503 & 1,3398 & {$[-0,099 ; 0,502]$} \\
\hline Confiabilidade no Serviço & 0,8054 & 0,1554 & 5,1845 & {$[0,495 ; 1,116]$} \\
\hline Estoque versus Exposição & 0,5254 & 0,1535 & 3,4428 & {$[0,221 ; 0,836]$} \\
\hline
\end{tabular}

A partir destes resultados, foram obtidas as probabilidades de aceitação do CDU para os varejistas com base nos na presença de seus atributos calculados de acordo com a pesquisa de preferência declarada (PD), apresentadas na Tabela 4. 
Tabela 4 - Probabilidade dos cenários de aceitação do CDU para os varejistas

\begin{tabular}{ll}
\hline \multicolumn{1}{c}{ Cenário } & Probabilidade Acumulada \\
\hline $\begin{array}{l}\text { Melhoria da Prestação de Serviço, Confiabilidade e do Espaço } \\
\text { para Exposição }\end{array}$ & $82 \%$ \\
\hline Melhoria da Confiabilidade e do Espaço para Exposição & $79 \%$ \\
\hline Melhoria da Prestação de Serviço e da Confiabilidade & $73 \%$ \\
\hline Melhoria da Confiabilidade & $69 \%$ \\
\hline Melhoria da Prestação de Serviço e do Espaço para Exposição & $67 \%$ \\
\hline Melhoria do Espaço para Exposiação & $63 \%$ \\
\hline $\begin{array}{l}\text { Custo com Melhoria da Prestação de Serviço, Confiabilidade e } \\
\text { do Espaço para Exposição }\end{array}$ & $60 \%$ \\
\hline $\begin{array}{l}\text { Custo com Melhoria da Confiabilidade e do Espaço para } \\
\text { Exposição }\end{array}$ & $55 \%$ \\
\hline Melhoria da Prestação de Serviço & $55 \%$ \\
\hline Custo com Melhoria da prestação de Serviço e da & $47 \%$ \\
Confiabilidade & $42 \%$ \\
\hline Custo com Melhoria da Confiabilidade & $40 \%$ \\
\hline Custo com Melhoria da prestação de Serviço e do Espaço para & \\
\hline Exposição & $35 \%$ \\
\hline Custo com Melhoria do Espaço para Exposição & $28 \%$ \\
\hline Custo com Melhoria da Prestação de Serviço & $24 \%$ \\
\hline Custo & \\
\hline
\end{tabular}

Como o custo é o atributo mais significativo para a adesão dos varejistas ao esquema de CDU, as probabilidades associadas com a presença dele apresentam baixa probabilidade de adesão ao CDU. Já quando este atributo não está presente, a probabilidade analisada aumenta consideravelmente, chegando a $82 \%$ quando todos os outros atributos são escolhidos. Este fato demonstra a importância da participação do poder público na implantação dos CDU, atuando, principalmente, com incentivos para a minimização dos custos que ele potencialmente pode acarretar. Os resultados apresentados na Tabela 4 permitiram delinear quatro cenários de análise:

- $100 \%$ de adesão, onde foi considerada uma configuração em que o uso deste esquema é obrigatório, isto é, totalmente regulamentado pela administração pública local;

- $82 \%$ de adesão, representando uma situação em que a adesão não é obrigatória, mas conta com subsídios governamentais que visam diminuir os custos econômicos do sistema;

- $60 \%$ de adesão, representando uma situação sem a presença dos incentivos governamentais; 
- $47 \%$ de adesão, representando uma situação pessimista, em que não haveria a adesão da maioria dos varejistas ao esquema de CDU em virtude da ausência de melhoria da prestação do serviço.

Para definir a demanda de cada um dos cenários, foi utilizado o cadastro de imóveis da região estudada, que aponta a existência de 13.730 estabelecimentos comerciais, incluindo bares, restaurantes, lojas de vestuário e calçados na região central de Belo Horizonte (PBH, 2012). A amostra definida nesta pesquisa considerou empresas com área total entre 20 e $500 \mathrm{~m}^{2}$, perfil observado através da pesquisa socioeconômica aplicada juntamente à PD, totalizando 3.787 pontos de demanda, que foram alocados à rede do TransCAD, para a etapa de aplicação do modelo de otimização.

\subsection{Proposição de cenários}

Nesta seção serão apresentados os cenários (base e proposto) que fundamentaram a aplicação da metodologia desenvolvida neste trabalho.

\section{Cenário base}

Nesta item, será caracterizado o cenário base que contempla a atual configuração da distribuição de cargas na região analisada. Nesta estrutura as cargas oriundas dos mais diversos destinos são dirigidas aos centros de distribuição de propriedade de varejistas, atacadistas e operadores logísticos. Nestas instalações, geralmente, as cargas são desagregadas para armazenagem e/ou para entrega aos seus destinos finais. Considerando o caso específico das cargas que têm como destino a região analisada neste trabalho, verifica-se que os produtos movimentados em veículos que não atendem as restrições de tamanho e peso regulamentadas pela prefeitura municipal devem, necessariamente, ser transferidos para locais de transbordo de carga como os centros de distribuição ou pontos de cross doking para uma posterior entrega aos seus locais de destino.

A Figura 4 mostra a organização da rede logística que retrata a estrutura utilizada para a distribuição de cargas em Belo Horizonte, analisando a movimentação de produto destes últimos até os varejistas situados na região analisada. 


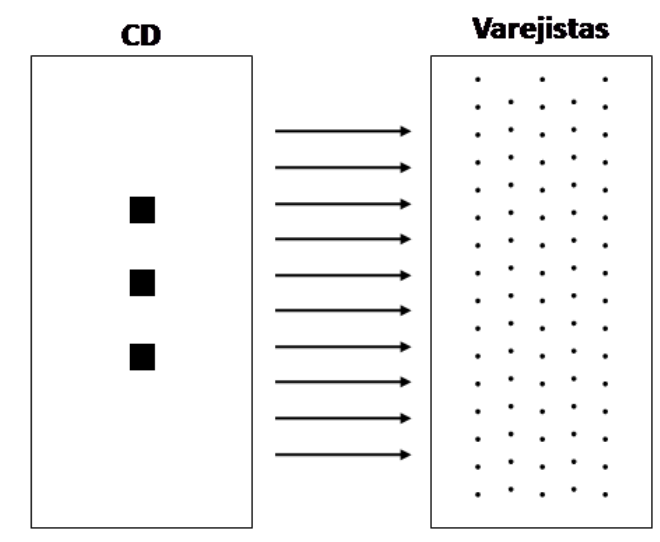

Figura 4 - Configuração atual da rede de distribuição ${ }^{4}$

Para definir o cenário base, as regiões com maior concentração de centros de distribuição foram identificadas, principalmente operadores logísticos que atuam na distribuição de cargas para a região com restrição de circulação de veículos de carga, notadamente, a área abrangida pela Avenida do Contorno no município de Belo Horizonte. Para isto, foi realizada uma análise da lista telefônica e consulta ao Sindicato das Empresas de Transportes de Carga de Minas Gerais (SETCEMG) onde se buscou catalogar a localização das empresas para uma posterior alocação em um mapa para análise das regiões mais relevantes em termos de concentração de transportadoras de cargas fracionadas e área total destinada às operações logísticas.

Nessa análise foram identificadas três importantes regiões de acordo com os critérios relatados. Em seguida, realizaram-se consultas às pessoas que atuam no mercado de distribuição de cargas no município como supervisores de empresas e motoristas. Nestas consultas, buscou-se identificar outras regiões relevantes para alocação na rede de distribuição base. No entanto, os entrevistados não adicionaram outras áreas importantes, confirmando a análise documental e a consulta ao SETCEMG. Assim, as três principais áreas identificadas foram inseridas como nós na rede de trabalho do TRANSCAD. Cada um destes nós representou a localização das empresas das regiões identificadas.

O segundo aspecto da caracterização do cenário base refere-se à análise em relação à proporção da demanda dos varejistas atendida por cada ponto identificado. Para definir a quantidade de carga que partiria destes pontos para a entrega aos varejistas, utilizou-se como critério a área de cada região. Desta forma, identificou-se a área total das três regiões caracterizadas e a demanda

\footnotetext{
${ }^{4}$ Fonte: autores (elaboração própria).
} 
dos varejistas que atuam na região analisada foi distribuída de forma proporcional a cada uma delas. Estes nós foram responsáveis pelo atendimento de $72 \%$ (área de 1,84 km²), 18\% (área de $0,94 \mathrm{~km}^{2}$ ) e $10 \%$ (área de $0,34 \mathrm{~km}^{2}$ ), da demanda dos varejistas representada na Figura 17 , respectivamente, pelos pontos 1, 3 e 2 . Com base nestas informações foi realizado um estudo de roteirização utilizando uma jornada de trabalho de 8 horas e uma frota homogênea com capacidade de $12 \mathrm{~m}^{3}$, volume médio de um veículo urbano de carga que atende as restrições de circulação regulamentadas pelo governo municipal conforme metodologia apresentada.

\section{Cenários propostos}

Neste item serão apresentados os cenários desenvolvidos tendo como referência a aplicação do modelo de centro de distribuição urbano proposto neste trabalho. Destaca-se que a estrutura atual de distribuição de cargas na cidade possui um nível de atendimento. Nele, as entregas são realizadas tendo como origem os centros de distribuição das empresas e como destino os varejistas. A configuração dos cenários propostos inclui mais um nível na rede de atendimento ou uma camada de nós na rede atual e a alteração da função dos nós apresentados no cenário base. Neste sentido, as mercadorias seguem de pontos de consolidação para os terminais de apoio e destes últimos para os varejistas conforme se observa na Figura 5 e será detalhado a seguir.

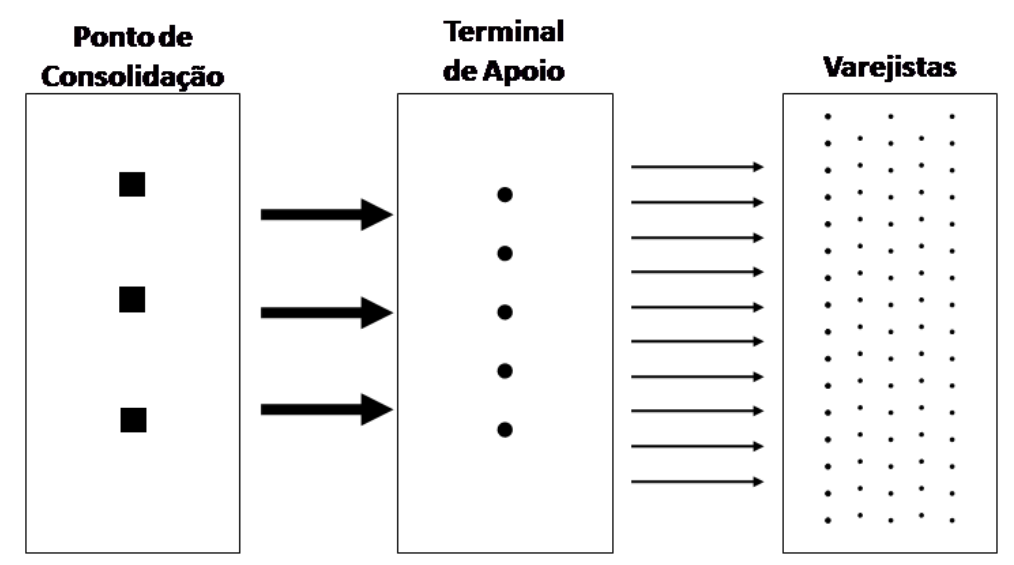

Figura 5 - Rede de atendimento dos cenários propostos ${ }^{5}$

É importante mencionar que a estrutura proposta estipulou uma nova configuração para a distribuição das cargas no centro urbano. Nesta nova formatação foram considerados os

\footnotetext{
${ }^{5}$ Fonte: autores (elaboração própria).
} 
mesmos nós citados no cenário base, contudo, com uma nova função, ou seja, representando pontos de consolidação das cargas oriundas de cada uma das vias de entrada do município. Destaca-se que Belo Horizonte possui quatro principais passagens de fluxos de cargas, conforme pode ser observado na Figura 6, representadas pelas BR-040 e BR-381 que formam a estrutura de entrada e saída de mercadorias na região analisada. Estas rodovias são interligadas pelo Anel Rodoviário por onde trafegam cerca de 100 mil veículos em um trecho de, aproximadamente, 27 quilômetros (BHTRANS, 2010).

Após a identificação dos fluxos de entrada e saída de produtos, analisou-se a influência destes na região de estudo por meio da Pesquisa Domiciliar de Origem e Destino (Pesquisa OD) realizada nos anos 2001 e 2002 pela Fundação João Pinheiro (2003) na região metropolitana de Belo Horizonte (RMBH) com intuito de determinar o nível de atendimento da demanda de cada ponto de consolidação. Esta influência foi medida pela quantidade de veículos de carga que passaram por cada fluxo de entrada de mercadorias e que tiveram como destino a região analisada. De acordo com a Pesquisa OD, constatou-se que 59\%, $12 \%, 8 \%$ e $21 \%$ foram provenientes, respectivamente, dos pontos 2, 4, 1 e 3 da Figura 6. Estes valores foram utilizados para definir a porcentagem da demanda estimada dos varejistas que cada um dos pontos de consolidação atenderia. Neste sentido, os pontos 2, 4, 1 e 3, atenderam, respectivamente, 59\%, $12 \%, 8 \%$ e $21 \%$ dos pedidos realizados pelos varejistas.

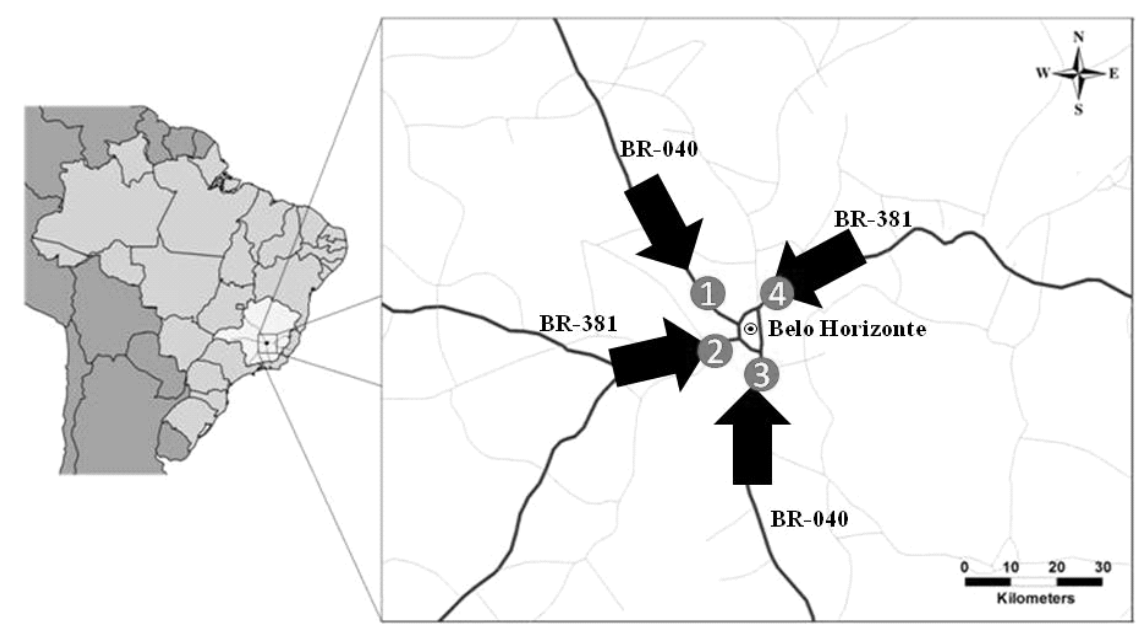

Figura 6 - Principais entradas para a cidade de Belo Horizonte (MG) ${ }^{6}$

Os pontos identificados na Figura 6 representam: BR 381 (ponto 2): entrada de veículos vindos do sul do estado e do país, como sul de Minas Gerais, São Paulo, Paraná, etc.; BR 381 (ponto

\footnotetext{
${ }^{6}$ Fonte: autores (elaboração própria).
} 
4): acesso de veículos originados, principalmente, do leste de Minas Gerais e Espírito Santo; BR 040 (ponto 1): ingresso de veículos provenientes, essencialmente, do norte do estado e da região centro-oeste do país; e, BR 040 (ponto 3): chegada de veículos procedentes, sobretudo, da zona da mata mineira e do Rio de Janeiro. É importante destacar que os pontos 2, 4 e 1 foram representados pelos mesmos nós do cenário base uma vez que estas regiões já possuíam uma importante concentração de atividades logísticas, conforme levantamento realizado. Nota-se que o ponto 3 foi adicionado à rede logística do esquema de CDU, mas não foi considerado uma região relevante na configuração base apresentada em função do baixo número de empresas instaladas. A motivação para a inclusão deste ponto se deu em virtude da análise da Pesquisa OD onde se verificou que existe um importante fluxo de veículos de carga (21\%) passando por esta localidade e tendo a região analisada como destino.

A configuração apresentada neste cenário possui dois níveis de agregação de cargas. O primeiro nível é representado pelos pontos de consolidação, responsáveis pelo agrupamento das cargas considerando toda a região analisada. Já o segundo nível é constituído pelos terminais de apoio que realizam a associação das cargas tendo em vista a sua região de cobertura dentro da região estudada definida no estudo de localização. Neste trabalho os pontos de consolidação são lugares fixos, conforme os nós determinados, ao passo que os terminais de apoio são instalações que foram estabelecidas de acordo com um número de locais candidatos e ainda foram objeto de variações em sua configuração como será demonstrado no estudo de localização realizado.

A configuração apresentada nesta seção teve como finalidade apresentar uma nova formatação para a distribuição de cargas na região analisada com a introdução de dois níveis de consolidação de cargas motivados pela análise dos fluxos de entrega de veículos. Nesta formatação buscou-se uma melhor organização dos processos logísticos da cidade com intuito de analisar o comportamento dos custos econômicos e ambientais e, consequentemente, verificar a sua contribuição para a mitigação das externalidades do transporte urbano de mercadorias.

\subsection{Modelo de otimização}

Neste item serão apresentados os resultados do modelo de otimização fundamentados nas ferramentas de localização e roteirização de veículos do TRANSCAD. O estudo de localização determinou o posicionamento dos terminais de apoio nos cenários propostos e o de roteamento 
definiu as viagens e os clientes alocados a cada um dos veículos utilizados nas duas camadas de atendimento.

Na estrutura proposta no cenário com pontos de consolidação, as cargas partem destes nós em direção aos terminais de apoio. Cada um dos terminais consolida as cargas originárias dos pontos de consolidação para realizar a entrega das mercadorias em sua região de atuação. Os pontos de consolidação e os centros de distribuição possuem uma posição previamente definida. Os varejistas também têm uma localização fixa, variando a quantidade atendida pelo modelo de CDU e pelo esquema atual. Já a posição dos terminais foi objeto do estudo de localização realizado neste trabalho uma vez que ela poderia variar em função da rede logística definida para cada cenário analisado.

O estudo de localização dos terminais de apoio teve como intuito determinar os melhores pontos dentre um conjunto de nós candidatos selecionado de acordo com a disponibilidade de instalações que poderiam atender a rede proposta. Para isso, foi utilizada a ferramenta de minimização do custo médio de serviço do TRANSCAD. Nesta ferramenta foram realizadas simulações para diferentes números de terminais de apoio, partindo da escolha de 8 até 1 instalação objetivando verificar a sensibilidade da quantidade de terminais em relação aos parâmetros econômicos e ambientais avaliados.

Concomitante ao estudo de localização foi realizado um estudo de roteirização que utilizou uma jornada de trabalho de oito horas para os veículos envolvidos nos dois níveis, sendo que o primeiro nível foi representado pelo deslocamento das mercadorias dos pontos de consolidação para os terminais de apoio e o segundo nível foi constituído pela movimentação dos produtos dos terminais de apoio até os varejistas. Vale mencionar que a capacidade da frota utilizada no primeiro nível foi de $45 \mathrm{~m}^{3}$, volume médio de um veículo truck, e no segundo nível foi de 12 $\mathrm{m}^{3}$, volume médio de um veículo urbano de carga consoante com a simulação feita no cenário base.

Verificou-se que entre 5 a 8 terminais de apoio, a variação nos parâmetros observados foi ínfima, sendo de, aproximadamente, 2\%. Observou-se então a convergência para uma quantidade máxima de cinco terminais de apoio uma vez que um número superior a este culmina no aumento da complexidade da rede logística além de elevar o seu custo de implantação sem uma contrapartida relevante em relação à redução dos impactos ambientais, 
aspecto fundamental na implementação do modelo de CDU. Desta forma, os cenários propostos para análise contaram com a escolha de 5, 4, 3, 2 e 1 terminal de apoio. Para cada cenário de adesão dos clientes foram realizadas variações na configuração da rede logística do esquema de CDU partindo da escolha de 5 até 1 terminal de apoio tendo em vista as estruturas dos cenários propostos. Estes cenários totalizaram 21 situações possíveis para o caso analisado com diferentes valores para os parâmetros econômicos e ambientais avaliados.

Vale destacar que em todos os cenários a demanda dos clientes foi totalmente atendida mesmo quando considerados níveis de adesão diferentes de $100 \%$. Neste sentido, presumindo um cenário com $82 \%$ de adesão dos varejistas, por exemplo, o modelo de CDU foi responsável pelo atendimento de $82 \%$ da movimentação de mercadorias para a região analisada. Já os $18 \%$ restantes foram atendidos pela estrutura atual de distribuição de cargas do município apresentada no cenário base.

Ressalta-se ainda que, conforme mencionado, a variação realizada nos cenários, refere-se ao número de varejistas que aderem ao sistema proposto e não à demanda atendida. Desta forma, um cenário com $60 \%$ de adesão pode ter uma demanda atendida superior ou inferior a este valor já que ela não foi distribuída de forma homogênea entre os varejistas, ou seja, respeitou-se a demanda do tipo de comércio calculada seguindo a PD realizada para o modelo de adesão.

\subsection{Avaliação econômica, logística e ambiental}

Neste tópico serão evidenciados os resultados das avaliações econômica e ambiental propostas para os cenários analisados neste trabalho. Em seguida será avaliada a influência da estrutura de atendimento e da adesão dos varejistas nos parâmetros econômicos e ambientais propostos visando identificar em que medida as variações estruturais e da demanda alteram o desempenho do modelo proposto. Por fim, será feito o detalhamento dos cálculos para as duas camadas de atendimento do melhor cenário identificado. Isto permitirá a análise do comportamento dos parâmetros avaliados em cada uma das camadas de atendimento de acordo com a variação do número de varejistas presentes no modelo. 


\section{Avaliação econômica e ambiental}

A Tabela 5 mostra os resultados consolidados das simulações realizadas do cenário base. Este cenário apresentou os piores resultados, dentre as configurações analisadas, em virtude dos altos valores de seus parâmetros quando comparados às melhores estruturas dos cenários propostos. Neste sentido, em relação aos parâmetros econômicos como, por exemplo, a quantidade de veículos entrando na região analisada e a distância percorrida, os valores auferidos foram, respectivamente, cerca de $103 \%$ e $153 \%$ superiores aos índices obtidos pelas melhores estruturas dos outros cenários. Já no que se refere aos quesitos ambientais, os resultados do cenário base são, aproximadamente, $54 \%$ maiores que os valores das estruturas de destaque dos cenários propostos.

Tabela 5 - Resultados do cenário base

\begin{tabular}{|c|c|c|c|c|c|c|c|c|c|}
\hline \multirow{2}{*}{\multicolumn{2}{|c|}{ Cenários Analisados }} & \multicolumn{8}{|c|}{ Parâmetros } \\
\hline & & \multicolumn{6}{|c|}{ Econômicos } & \multicolumn{2}{|c|}{ Ambientais } \\
\hline $\begin{array}{l}\text { Número } \\
\text { de } \\
\text { Terminais } \\
\text { de Apoio }\end{array}$ & $\begin{array}{l}\text { Percentual } \\
\text { de Adesão }\end{array}$ & $\begin{array}{c}\text { Número } \\
\text { de } \\
\text { Veículos }\end{array}$ & $\begin{array}{c}\text { Distância } \\
\text { Total } \\
(\mathbf{K m})\end{array}$ & $\begin{array}{c}\text { Tempo } \\
\text { Total (h) }\end{array}$ & $\begin{array}{l}\text { Ocupação } \\
\text { da Frota }\end{array}$ & $\begin{array}{c}\text { Número } \\
\text { de } \\
\text { Rotas }\end{array}$ & $\begin{array}{r}\text { Utilização } \\
\text { da Frota }\end{array}$ & $\begin{array}{c}\text { Consumo de } \\
\text { Combustível } \\
\text { (l) }\end{array}$ & $\begin{array}{c}\text { Emissão } \\
\text { de } \\
\text { Poluentes } \\
\text { (ton) }\end{array}$ \\
\hline- & $100 \%$ & 181 & 11.854 & 1.344 & $93 \%$ & 399 & $93 \%$ & 1.976 & 5,29 \\
\hline
\end{tabular}

Nota: $\mathrm{km}=$ Quilômetro $\mathrm{h}=$ Hora $\mathrm{l}=$ Litros ton $=$ Toneladas Métricas

A Tabela 6 mostra os resultados consolidados das simulações realizadas para os cenários considerando o modelo de CDU proposto neste trabalho. A coluna estrutura desta tabela refere-se a cada combinação entre a quantidade de terminais de apoio e o percentual de adesão dos varejistas. Neste sentido, foram avaliadas 20 configurações da rede logística de atendimento para esse cenário. É importante destacar que em todos os resultados apresentados nessa tabela considerou-se o atendimento de toda a demanda dos varejistas, ou seja, nas configurações com adesão inferior a 100\%, por exemplo, uma estrutura com $82 \%$ de adesão, considerou-se que $82 \%$ dos varejistas seriam atendidos pelo esquema de CDU e os $18 \%$ restantes receberiam seus produtos pela forma atual de distribuição, que foi representada pelo cenário base. Desta forma, os resultados econômicos e ambientais apresentados nessa tabela referem-se ao impacto do CDU na distribuição urbana da região analisada em uma forma ampla e não somente uma avaliação isolada do modelo. Isto porque foram simulados e compilados os resultados tendo em vista o atendimento de todos os varejistas presentes na rede de atendimento proposta neste trabalho. 
Analisando os melhores resultados para cada parâmetro avaliado de acordo com a relação entre o cenário base e os cenários propostos, observa-se algumas estruturas que se destacaram. Em relação ao número de veículos, houve uma redução de 110,5\% nas estruturas 8,12 e 16. No que se refere à ocupação da frota, a estrutura 4 teve um desempenho interessante uma vez que o valor deste quesito é $3 \%$ superior ao cenário base. A ociosidade do tempo da frota para a estrutura 11 foi $25,8 \%$ inferior ao cenário analisado. Já a estrutura 20 apresentou o melhor desempenho para distância total (160,3\%), o tempo total (109,9\%), o número de rotas $(21,3 \%)$, o consumo de combustível $(59,4 \%)$ e a emissão de poluentes $(59,4 \%)$ dado que os valores foram percentualmente vantajosos comparados ao cenário base.

Tabela 6 - Resultados consolidados dos cenários propostos

\begin{tabular}{|c|c|c|c|c|c|c|c|c|c|c|}
\hline \multirow{2}{*}{\multicolumn{2}{|c|}{ Cenários Analisados }} & \multicolumn{9}{|c|}{ Parâmetros } \\
\hline & & \multicolumn{6}{|c|}{ Econômicos } & \multicolumn{2}{|c|}{ Ambientais } & \multirow[b]{2}{*}{ Estrutura } \\
\hline $\begin{array}{c}\text { Número de } \\
\text { Terminais } \\
\text { de Apoio }\end{array}$ & $\begin{array}{l}\text { Percentual } \\
\text { de Adesão }\end{array}$ & $\begin{array}{c}\text { Número } \\
\text { de } \\
\text { Veículos }\end{array}$ & $\begin{array}{c}\text { Distância } \\
\text { Total } \\
\text { (Km) }\end{array}$ & $\left|\begin{array}{c}\text { Tempo } \\
\text { Total (h) }\end{array}\right|$ & $\begin{array}{c}\text { Ocupação } \\
\text { da Frota }\end{array}$ & $\begin{array}{c}\text { Número } \\
\text { de Rotas }\end{array}$ & $\begin{array}{r}\text { Utilização } \\
\text { da Frota }\end{array}$ & $\begin{array}{c}\text { Consumo de } \\
\text { Combustível } \\
\text { (l) }\end{array}$ & $\begin{array}{c}\text { Emissão } \\
\text { de } \\
\text { Poluentes } \\
\text { (ton) }\end{array}$ & \\
\hline \multirow{4}{*}{1} & $47 \%$ & 138 & 8.957 & 1.025 & $94 \%$ & 446 & $93 \%$ & 1.699 & 4,54 & 1 \\
\hline & $60 \%$ & 124 & 8.145 & 933 & $95 \%$ & 454 & $94 \%$ & 1.611 & 4,31 & 2 \\
\hline & $82 \%$ & 105 & 6.810 & 787 & $95 \%$ & 478 & $94 \%$ & 1.483 & 3,97 & 3 \\
\hline & $100 \%$ & 87 & 5.206 & 651 & $96 \%$ & 495 & $94 \%$ & 1.314 & 3,51 & 4 \\
\hline \multirow{4}{*}{2} & $47 \%$ & 137 & 8.811 & 1.023 & $94 \%$ & 446 & $93 \%$ & 1.692 & 4,53 & 5 \\
\hline & $60 \%$ & 125 & 7.962 & 931 & $95 \%$ & 456 & $93 \%$ & 1.608 & 4,30 & 6 \\
\hline & $82 \%$ & 105 & 6.538 & 784 & $95 \%$ & 478 & $93 \%$ & 1.468 & 3,93 & 7 \\
\hline & $100 \%$ & 86 & 4.859 & 644 & $96 \%$ & 497 & $94 \%$ & 1.289 & 3,45 & 8 \\
\hline \multirow{4}{*}{3} & $47 \%$ & 137 & 8.810 & 1.024 & $94 \%$ & 447 & $93 \%$ & 1.687 & 4,51 & 9 \\
\hline & $60 \%$ & 126 & 8.020 & 932 & $94 \%$ & 459 & $92 \%$ & 1.618 & 4,33 & 10 \\
\hline & $82 \%$ & 104 & 6.564 & 785 & $94 \%$ & 481 & $94 \%$ & 1.471 & 3,94 & 11 \\
\hline & $100 \%$ & 86 & 4.882 & 644 & $95 \%$ & 500 & $94 \%$ & 1.288 & 3,45 & 12 \\
\hline \multirow{4}{*}{4} & $47 \%$ & 143 & 8.771 & 1.024 & $94 \%$ & 448 & $89 \%$ & 1.686 & 4,51 & 13 \\
\hline & $60 \%$ & 126 & 7.911 & 932 & $94 \%$ & 459 & $92 \%$ & 1.597 & 4,27 & 14 \\
\hline & $82 \%$ & 105 & 6.420 & 782 & $94 \%$ & 483 & $93 \%$ & 1.445 & 3,86 & 15 \\
\hline & $100 \%$ & 86 & 4.735 & 644 & $95 \%$ & 501 & $94 \%$ & 1.266 & 3,39 & 16 \\
\hline \multirow{4}{*}{5} & $47 \%$ & 138 & 8.697 & 1.024 & $93 \%$ & 451 & $93 \%$ & 1.677 & 4,49 & 17 \\
\hline & $60 \%$ & 126 & 7.865 & 933 & $93 \%$ & 464 & $93 \%$ & 1.596 & 4,27 & 18 \\
\hline & $82 \%$ & 105 & 6.318 & 782 & $94 \%$ & 485 & $93 \%$ & 1.432 & 3,83 & 19 \\
\hline & $100 \%$ & 88 & 4.554 & 641 & $94 \%$ & 507 & $91 \%$ & 1.239 & 3,32 & 20 \\
\hline
\end{tabular}

\section{Avaliação da rede}

No item analisado anteriormente, verificou-se que os cenários propostos apresentaram um desempenho significativamente superior em relação aos parâmetros econômicos e ambientais, associada à estrutura logística proposta em cada cenário, ou seja, a presença dos terminais de apoio, e, sobretudo, pela adesão dos varejistas ao esquema de CDU. Neste item, será quantificada e avaliada a influência destes fatores sobre os resultados dos parâmetros 
econômicos e ambientais propostos neste trabalho. Esta quantificação da influência da estrutura logística (número de terminais de apoio) e da adesão dos varejistas nos parâmetros econômicos e ambientais foi realizada através da análise do coeficiente de variação (CV). O CV pode ser interpretado como a variabilidade dos dados em relação à média. Assim, quanto menor o $\mathrm{CV}$, mais homogêneo é o conjunto de dados.

Considerando o percentual de adesão e os resultados obtidos para os parâmetros econômicos e ambientais na alteração do número de terminais de apoio, calculou-se o coeficiente de variação, resultado da razão entre o desvio padrão dos valores dos parâmetros pela média dos valores dos parâmetros, cujos resultados estão apresentados na Tabela 7. O parâmetro utilização da frota obteve o maior valor do CV (6,11\%), indicando homogeneidade dos dados. Isto permite concluir que a mudança do número de terminais logísticos não acarreta uma variabilidade significativa dos resultados econômicos e ambientais do CDU.

Tabela 7 - Variação da estrutura logística para o cenário do modelo de CDU proposto

\begin{tabular}{|c|c|c|c|c|c|c|c|c|c|}
\hline \multirow{2}{*}{\multicolumn{2}{|c|}{ Cenários Analisados }} & \multicolumn{8}{|c|}{ Parâmetros } \\
\hline & & \multicolumn{6}{|c|}{ Econômicos } & \multicolumn{2}{|c|}{ Ambientais } \\
\hline $\begin{array}{c}\text { Número de } \\
\text { Terminais de } \\
\text { Apoio }\end{array}$ & $\begin{array}{l}\text { Percentual } \\
\text { de Adesão }\end{array}$ & $\begin{array}{c}\text { Número } \\
\text { de } \\
\text { Veículos }\end{array}$ & $\begin{array}{c}\text { Distância } \\
\text { Total } \\
(\mathbf{K m})\end{array}$ & \begin{tabular}{|c} 
Tempo \\
Total (h)
\end{tabular} & $\begin{array}{c}\text { Ocupação } \\
\text { da Frota }\end{array}$ & $\begin{array}{l}\text { Número } \\
\text { de Rotas }\end{array}$ & $\begin{array}{c}\text { Utilização } \\
\text { da Frota }\end{array}$ & $\begin{array}{c}\text { Consumo de } \\
\text { Combustível } \\
\text { (l) }\end{array}$ & $\begin{array}{c}\text { Emissão de } \\
\text { Poluentes } \\
\text { (ton) }\end{array}$ \\
\hline 1 & \multirow{5}{*}{$47 \%$} & 138 & 8.957 & 1.025 & $94 \%$ & 446 & $93 \%$ & 1.699 & 4,54 \\
\hline 2 & & 137 & 8.811 & 1.023 & $94 \%$ & 446 & $93 \%$ & 1.692 & 4,53 \\
\hline 3 & & 137 & 8.810 & 1.024 & $94 \%$ & 447 & $93 \%$ & 1.687 & 4,51 \\
\hline 4 & & 143 & 8.771 & 1.024 & $94 \%$ & 448 & $89 \%$ & 1.686 & 4,51 \\
\hline 5 & & 138 & 8.697 & 1.024 & $93 \%$ & 451 & $93 \%$ & 1.677 & 4,49 \\
\hline \multicolumn{2}{|c|}{ Coeficiente de Variação } & $1,62 \%$ & $0,96 \%$ & $0,04 \%$ & $0,41 \%$ & $0,41 \%$ & $1,58 \%$ & $0,43 \%$ & $0,43 \%$ \\
\hline 1 & \multirow{5}{*}{$60 \%$} & 124 & 8.145 & 933 & $95 \%$ & 454 & $94 \%$ & 1.611 & 4,31 \\
\hline 2 & & 125 & 7.962 & 931 & $95 \%$ & 456 & $93 \%$ & 1.608 & 4,30 \\
\hline 3 & & 126 & 8.020 & 932 & $94 \%$ & 459 & $92 \%$ & 1.618 & 4,33 \\
\hline 4 & & 126 & 7.911 & 932 & $94 \%$ & 459 & $92 \%$ & 1.597 & 4,27 \\
\hline 5 & & 126 & 7.865 & 933 & $93 \%$ & 464 & $93 \%$ & 1.596 & 4,27 \\
\hline \multicolumn{2}{|c|}{ Coeficiente de Variação } & $0,64 \%$ & $1,22 \%$ & $0,09 \%$ & $0,74 \%$ & $0,74 \%$ & $0,64 \%$ & $0,51 \%$ & $0,51 \%$ \\
\hline 1 & \multirow{5}{*}{$82 \%$} & 105 & 6.810 & 787 & $95 \%$ & 478 & $6 \%$ & 1.483 & 3,97 \\
\hline 2 & & 105 & 6.538 & 784 & $95 \%$ & 478 & $7 \%$ & 1.468 & 3,93 \\
\hline 3 & & 104 & 6.564 & 785 & $94 \%$ & 481 & $6 \%$ & 1.471 & 3,94 \\
\hline 4 & & 105 & 6.420 & 782 & $94 \%$ & 483 & $7 \%$ & 1.445 & 3,86 \\
\hline 5 & & 105 & 6.318 & 782 & $94 \%$ & 485 & $7 \%$ & 1.432 & 3,83 \\
\hline \multicolumn{2}{|c|}{ Coeficiente de Variação } & $0,38 \%$ & $2,53 \%$ & $0,24 \%$ & $0,57 \%$ & $0,57 \%$ & $6,89 \%$ & $1,27 \%$ & $1,27 \%$ \\
\hline 1 & \multirow{5}{*}{$100 \%$} & 87 & 5.206 & 651 & $96 \%$ & 495 & $6 \%$ & 1.314 & 3,51 \\
\hline 2 & & 86 & 4.859 & 644 & $96 \%$ & 497 & $6 \%$ & 1.289 & 3,45 \\
\hline 3 & & 86 & 4.882 & 644 & $95 \%$ & 500 & $6 \%$ & 1.288 & 3,45 \\
\hline 4 & & 86 & 4.735 & 644 & $95 \%$ & 501 & $6 \%$ & 1.266 & 3,39 \\
\hline 5 & & 88 & 4.554 & 641 & $94 \%$ & 507 & $9 \%$ & 1.239 & 3,32 \\
\hline \multicolumn{2}{|c|}{ Coeficiente de Variação } & $0,92 \%$ & $4,41 \%$ & $0,53 \%$ & $0,82 \%$ & $0,82 \%$ & $15,32 \%$ & $1,96 \%$ & $1,96 \%$ \\
\hline
\end{tabular}

Nota: $\mathrm{km}=$ Quilômetro $\mathrm{h}=$ Hora $\mathrm{l}=$ Litros ton $=$ Toneladas Métricas 
Além disso, também calculou-se o coeficiente de variação fixando o número de terminais de apoio e os resultados obtidos para os parâmetros econômicos e ambientais na alteração do percentual de adesão dos varejistas, cujos resultados estão apresentados na Tabela 8. Os coeficientes de variação são mais significativos para a maioria dos parâmetros avaliados, com exceção da ocupação e utilização da frota. Isto indica que a redução da adesão dos varejistas acarreta uma variabilidade relevante dos resultados econômicos e ambientais analisados. É importante destacar que esta tabela mostra os resultados tendo em vista toda a estrutura de distribuição de cargas na área analisada, incluindo as cargas que passam pelo modelo de CDU e pela configuração atual do município para os cenários com adesão inferior a 100\%. Assim, verifica-se que os benefícios do modelo de CDU para a região analisada são potencialmente reduzidos em função da sua sensibilidade à variação da adesão dos varejistas.

Tabela 8 - Variação da adesão dos varejistas para o cenário do modelo proposto

\begin{tabular}{|c|c|c|c|c|c|c|c|c|c|}
\hline \multirow{2}{*}{\multicolumn{2}{|c|}{ Cenários Analisados }} & \multicolumn{8}{|c|}{ Parâmetros } \\
\hline & & \multicolumn{6}{|c|}{ Econômicos } & \multicolumn{2}{|c|}{ Ambientais } \\
\hline $\begin{array}{c}\text { Número de } \\
\text { Terminais de } \\
\text { Apoio }\end{array}$ & $\begin{array}{l}\text { Percentual } \\
\text { de Adesão }\end{array}$ & $\begin{array}{c}\text { Número } \\
\text { de } \\
\text { Veículos }\end{array}$ & \begin{tabular}{|c|} 
Distância \\
Total \\
$(\mathrm{Km})$
\end{tabular} & \begin{tabular}{|c|} 
Tempo \\
Total (h)
\end{tabular} & $\begin{array}{c}\text { Ocupação } \\
\text { da Frota }\end{array}$ & $\begin{array}{l}\text { Número } \\
\text { de Rotas }\end{array}$ & $\begin{array}{c}\text { Utilização } \\
\text { da Frota }\end{array}$ & $\begin{array}{c}\text { Consumo de } \\
\text { Combustível } \\
\text { (l) }\end{array}$ & $\begin{array}{c}\text { Emissão de } \\
\text { Poluentes } \\
\text { (ton) }\end{array}$ \\
\hline \multirow{4}{*}{1} & $47 \%$ & 138 & 8.957 & 1.025 & $94 \%$ & 446 & $93 \%$ & 1.699 & 4,54 \\
\hline & $60 \%$ & 124 & 8.145 & 933 & $95 \%$ & 454 & $94 \%$ & 1.611 & 4,31 \\
\hline & $82 \%$ & 105 & 6.810 & 787 & $95 \%$ & 478 & $94 \%$ & 1.483 & 3,97 \\
\hline & $100 \%$ & 87 & 5.206 & 651 & $96 \%$ & 495 & $94 \%$ & 1.314 & 3,51 \\
\hline \multicolumn{2}{|c|}{ Coeficiente de Variação } & $16,98 \%$ & $19,53 \%$ & $16,74 \%$ & $0,78 \%$ & $4,15 \%$ & $0,48 \%$ & $9,50 \%$ & $9,50 \%$ \\
\hline \multirow{4}{*}{2} & $47 \%$ & 137 & 8.811 & 1.023 & $94 \%$ & 446 & $93 \%$ & 1.692 & 4,53 \\
\hline & $60 \%$ & 125 & 7.962 & 931 & $95 \%$ & 456 & $93 \%$ & 1.608 & 4,30 \\
\hline & $82 \%$ & 105 & 6.538 & 784 & $95 \%$ & 478 & $93 \%$ & 1.468 & 3,93 \\
\hline & $100 \%$ & 86 & 4.859 & 644 & $96 \%$ & 497 & $94 \%$ & 1.289 & 3,45 \\
\hline \multicolumn{2}{|c|}{ Coeficiente de Variação } & $17,17 \%$ & $21,29 \%$ & $17,05 \%$ & $0,64 \%$ & $4,21 \%$ & $0,24 \%$ & $10,08 \%$ & $10,08 \%$ \\
\hline \multirow{4}{*}{3} & $47 \%$ & 137 & 8.810 & 1.024 & $94 \%$ & 447 & $93 \%$ & 1.687 & 4,51 \\
\hline & $60 \%$ & 126 & 8.020 & 932 & $94 \%$ & 459 & $92 \%$ & 1.618 & 4,33 \\
\hline & $82 \%$ & 104 & 6.564 & 785 & $94 \%$ & 481 & $94 \%$ & 1.471 & 3,94 \\
\hline & $100 \%$ & 86 & 4.882 & 644 & $95 \%$ & 500 & $94 \%$ & 1.288 & 3,45 \\
\hline \multicolumn{2}{|c|}{ Coeficiente de Variação } & $17,41 \%$ & $21,19 \%$ & $17,07 \%$ & $0,54 \%$ & $4,32 \%$ & $0,69 \%$ & $10,08 \%$ & $10,08 \%$ \\
\hline \multirow{4}{*}{4} & $47 \%$ & 143 & 8.771 & 1.024 & $94 \%$ & 448 & $89 \%$ & 1.686 & 4,51 \\
\hline & $60 \%$ & 126 & 7.911 & 932 & $94 \%$ & 459 & $92 \%$ & 1.597 & 4,27 \\
\hline & $82 \%$ & 105 & 6.420 & 782 & $94 \%$ & 483 & $93 \%$ & 1.445 & 3,86 \\
\hline & $100 \%$ & 86 & 4.735 & 644 & $95 \%$ & 501 & $94 \%$ & 1.266 & 3,39 \\
\hline \multicolumn{2}{|c|}{ Coeficiente de Variação } & $18,68 \%$ & $22,06 \%$ & $17,12 \%$ & $0,54 \%$ & $4,37 \%$ & $1,74 \%$ & $10,65 \%$ & $10,65 \%$ \\
\hline \multirow{4}{*}{5} & $47 \%$ & 138 & 8.697 & 1.024 & $93 \%$ & 451 & $93 \%$ & 1.677 & 4,49 \\
\hline & $60 \%$ & 126 & 7.865 & 933 & $93 \%$ & 464 & $93 \%$ & 1.596 & 4,27 \\
\hline & $82 \%$ & 105 & 6.318 & 782 & $94 \%$ & 485 & $93 \%$ & 1.432 & 3,83 \\
\hline & $100 \%$ & 88 & 4.554 & 641 & $94 \%$ & 507 & $91 \%$ & 1.239 & 3,32 \\
\hline \multicolumn{2}{|c|}{ Coeficiente de Variação } & $16,82 \%$ & $23,04 \%$ & $17,31 \%$ & $0,38 \%$ & $4,46 \%$ & $0,89 \%$ & $11,27 \%$ & $11,27 \%$ \\
\hline
\end{tabular}

Nota: $\mathrm{km}=$ Quilômetro $\mathrm{h}=$ Hora $\mathrm{l}=$ Litros ton $=$ Toneladas Métricas 
Os resultados apresentados nas Tabelas 7 e 8 permitem concluir que a estrutura logística e a demanda dos varejistas possuem o mesmo nível de influência sobre estes cenários uma vez que o comportamento da média dos $\mathrm{CV}$ dos parâmetros propostos é praticamente equivalente. Desta forma, a sensibilidade dos resultados econômicos e ambientais em decorrência da variação da configuração logística ou da adesão dos varejistas tende a ser uniforme, oscilando quase na mesma proporção independentemente da escolha do cenário proposto.

É importante destacar que a adesão dos varejistas ao modelo de CDU tem um papel fundamental para a diminuição das externalidades negativas da distribuição de carga no ambiente urbano e da redução dos custos na cadeia de suprimentos. Isto porque, conforme as análises realizadas, os parâmetros econômicos e ambientais possuem uma significativa sensibilidade em relação à variação dos cenários de adesão apresentados. Os terminais de apoio também possuem uma função importante na estrutura logística do CDU na medida em que eles são responsáveis pelo agrupamento das mercadorias da primeira camada de roteirização possibilitando uma composição de frota que é essencial para a redução dos custos de distribuição das empresas e dos impactos ambientais das atividades de entrega urbana de cargas.

Contudo, a quantidade de terminais de apoio não interfere preponderantemente os resultados dos parâmetros econômicos ambientais em virtude do baixo índice dos coeficientes de variação apontados nas análises anteriormente realizadas. Desta forma, independente da estrutura logística do modelo de CDU, ou seja, do número de terminais de apoio envolvidos no esquema, é essencial estabelecer estratégias que garantam a adesão dos varejistas, como por exemplo, a divulgação dos potenciais benefícios do esquema e a minimização de possíveis custos adicionais oriundos de novas instalações na cadeia de suprimentos. Vale frisar que o terminal de apoio pode gerar um aumento de tráfego de veículos na região em que foi localizado. A diminuição do número de terminais pode culminar no aumento da estrutura das outras instalações, dada uma quantidade fixa de carga a ser movimentada, que pode trazer transtornos à população em virtude do potencial incremento de veículos em circulação na região em que foram localizados. 


\subsection{Detalhamento da avaliação econômica e ambiental por camadas}

Neste tópico serão evidenciados os resultados de alguns parâmetros da avaliação econômica e ambiental para os quatro cenários de adesão dos varejistas baseada na rede de logística com cinco terminais de apoio, mais especificamente, as estruturas 17 a 20 da Tabela 6. Neste sentido, foi feito o detalhamento dos cálculos para os dois níveis de atendimento, com intuito de analisar o comportamento dos parâmetros avaliados em cada um deles tendo em vista a variação do número de varejistas presentes no modelo. Além disto, foram comparados estes resultados com o cenário atual da distribuição de carga na área analisada visando explorar o potencial que o modelo oferece em contraposição com o cenário atual do município.

\section{Número de veículos}

O número de veículos utilizados no primeiro nível, ou seja, para o transporte entre os terminais de apoio e os clientes foi de 63 veículos. Já entre a CDU e os terminais, este número foi de 25 , totalizando 88 veículos. Para o cenário base, a quantidade calculada foi de 181 veículos. Comparando-se os cenários, percebe-se uma redução deste quesito de 51,4\%. Contudo, considerando-se apenas a área urbana, onde ocorrem os maiores problemas com congestionamento, notadamente representada pelo primeiro nível de atendimento, a redução é de 65,2\%. Neste sentido, 118 veículos deixariam de circular na área central com a implantação do CDU, fato que demonstra a vantagem desta iniciativa, não somente como uma forma de reduzir os custos das empresas na distribuição de cargas, mas também para mitigar os graves problemas que o excesso de veículos em circulação acarreta nas grandes cidades.

\section{Distância percorrida}

Para o cenário da estrutura 20 da Tabela 5 verificou-se que a distância percorrida pelos veículos no primeiro nível foi de $1.673 \mathrm{~km} \mathrm{e}$, no segundo, de $2.881 \mathrm{~km}$, totalizando $4.554 \mathrm{~km}$. O modelo de CDU proposto acarreta uma redução de 61,6\% no percurso realizado pelos veículos de carga, uma vez que, no cenário base, a distância percorrida foi de $11.855 \mathrm{~km}$. A redução de distância percorrida, além de diminuir os custos da distribuição urbana, é importante para a conservação das vias e um elemento fundamental para a redução do consumo de combustível. 


\section{Tempo total de distribuição}

O tempo total de distribuição engloba: $(i)$ o tempo gasto nas operações de carga e descarga nos clientes; (ii) o tempo gasto com o carregamento dos veículos nos terminais de apoio, nos pontos de consolidação e CDU's convencionais; (iii) o tempo de viagem entre os varejistas e destes para os terminais de apoio ou CDU's convencionais, e (iv) o tempo de viagem dos terminais de apoio para os pontos de consolidação. No cenário da estrutura 20 da Tabela 5 , o tempo de distribuição no primeiro nível foi de 463 horas e de 178 horas no segundo nível, totalizando 641 horas. Já no cenário base, o tempo total de distribuição foi de 1.344 horas. Isto representa que o modelo proposto acarreta uma redução de $52,4 \%$ em relação ao tempo total do panorama atual de distribuição de cargas da cidade na área analisada.

\section{Número de rotas}

O modelo de CDU acarretou um acréscimo no número de rotas comparado ao panorama atual de distribuição de cargas do município. Esta elevação foi de, respectivamente, 21,30\%, 17,7\%, $16,3 \%$ e 13\%, para os cenários com 100\%, 87\%, 60\% e 47\% de adesão. Estes resultados podem ser explicados, em parte, pelo aumento da complexidade do sistema em que é necessária a roteirização em dois níveis de atendimento e por um melhor aproveitamento da frota utilizada uma vez que no cenário base são alocadas, em média, 2,2 rotas por veículo, já, por exemplo, na simulação com $100 \%$ de adesão, este valor passa para 5,8 rotas por veículo.

\section{Consumo de combustível}

O consumo de combustível se configura como um parâmetro de análise essencial no modelo de CDU, tendo em vista que se trata do uso de uma fonte de energia não-renovável e, consequentemente, a sua redução acarreta benefícios para toda a sociedade. Vale mencionar que os cálculos realizados basearam em um fator de consumo médio de $6 \mathrm{~km} / \mathrm{l}$ para os veículos de menor porte e $3 \mathrm{~km} / \mathrm{l}$ para os equipamentos com capacidade de carga ampliada e na distância percorrida em cada nível de análise. Estes valores estão congruentes com o tipo de frota utilizada e o tipo de atividade realizada pelos veículos segundo a prática das empresas que operam na região analisada. Destaca-se uma significativa redução no consumo de combustível em relação ao cenário atual, mesmo este tendo sido calculado, conforme anteriormente mencionado, com base na melhor situação de roteirização do ponto de vista da cidade. Esta 
redução foi de, respectivamente, $37,27 \%, 27,5 \%, 19,2 \%$ e 15,1\%, para os cenários de adesão de $100 \%, 82 \%, 60 \%$ e $47 \%$.

\section{Emissão de poluentes}

A emissão de poluentes traz consequências negativas para toda a sociedade, como os problemas respiratórios e o aquecimento global, que culminam na diminuição da qualidade de vida da população. Assim, um dos objetivos fundamentais do modelo de CDU é a redução da emissão de poluentes. Os resultados da emissão de poluentes foram bem parecidos aos do consumo de combustíveis uma vez que a base de cálculo da ferramenta utilizada considera a quantidade de combustível em cada nível analisado. Neste sentido, a redução da emissão de poluentes dos cenários propostos, em relação ao panorama base, foi de, respectivamente, 37,27\%, 27,5\%, $19,2 \%$ e $15,1 \%$, para os cenários de adesão de $100 \%, 82 \%, 60 \%$ e $47 \%$. Já a sensibilidade da emissão em no que se refere à variação da adesão de varejistas foi, em média, cerca de, $27 \%$ nos dois níveis e $38 \%$ no modelo de atendimento atual.

\section{Conclusão}

Este artigo apresentou uma proposta metodológica para avaliar os impactos econômicos e ambientais de um centro de distribuição urbano de mercadorias (CDU), aplicado à área central de Belo Horizonte que possui restrições de acesso aos veículos de carga e problemas com o tráfego de veículos de carga. É importante mencionar que esta alternativa configura-se como uma das soluções da logística urbana para atenuar os problemas gerados pela distribuição de mercadorias nas cidades.

A metodologia proposta considerou configurações alternativas para a realização das entregas no centro urbano do município com intuito de reduzir as externalidades negativas do transporte de carga e os custos de distribuição para a cadeia de suprimentos. Os resultados apontaram que o modelo desenvolvido pode trazer uma substancial melhoria para os agentes envolvidos na distribuição de mercadorias, como a sociedade, transportadores e varejistas, comprovando que o CDU se constitui como uma importante iniciativa para otimizar os processos logísticos na cidade analisada em virtude dos resultados dos parâmetros econômicos e ambientais apresentados. Desta forma, foram alcançados os objetivos que orientaram o desenvolvimento 
deste trabalho.

Os parâmetros econômicos e ambientais propostos neste trabalho foram desenvolvidos considerando a bibliografia pesquisa. Neste sentido, este trabalho detalhou os elementos para analisar o comportamento dos impactos econômicos e ambientais em decorrência das alterações das estruturas logísticas conforme os cenários analisados.

É importante destacar que a formatação da estrutura logística de abastecimento na cidade analisada e o estudo da adesão dos varejistas ao modelo de CDU são os princípios fundamentais nas análises realizadas neste trabalho. Na formatação da estrutura do modelo de CDU foram propostos cenários com a presença de duas camadas de atendimento, a primeira, refere-se ao fluxo de mercadorias dos pontos previamente definidos até os locais de transferência de cargas, ou seja, os terminais de apoio. Já a segunda, constituiu o caminho dos produtos dos terminais de apoio até os varejistas, instalados na região analisada. A posição dos terminais de apoio foi determinada pelo estudo de localização de instalações. Além disto, foi feito um estudo de roteirização para as duas camadas propostas. Destaca-se que o estudo de adesão dos varejistas definiu a demanda destes agentes que fundamentou os estudos de localização e roteirização realizados.

Além disso, foram instituídos dois cenários que fundamentaram as simulações realizadas. $\mathrm{O}$ primeiro cenário, ou cenário base, refletiu a estrutura atual da distribuição de cargas no município. No segundo, ou nos cenários propostos, foram realizadas alterações na estrutura da rede de abastecimento e na demanda dos varejistas, buscando organizar o processo logístico na cidade desde o fluxo de entrada das mercadorias até a entrega aos varejistas localizados na região pesquisada.

A avaliação da adesão dos varejistas na região central de Belo Horizonte em relação à utilização do CDU determinou cenários que alteraram a quantidade destes agentes presentes no modelo proposto. Verificou-se que estes agentes aprovam a iniciativa pesquisada desde que ela não acarrete aumento nos custos de seus empreendimentos. Destaca-se que no Brasil não existem registros de implantação de CDU congruente com o conceito apresentado neste trabalho. Os casos de implantação deste sistema em alguns países, como França, Inglaterra e Alemanha, contou com uma presença importante do setor público, atuando, principalmente, com incentivos para a minimização dos custos que este modelo potencialmente pode acarretar. Os 
resultados desta pesquisa indicam que esta participação pode se justificar também para a realidade brasileira na medida em que o nível de adesão dos varejistas aumenta substancialmente quando o modelo é implantado sem ônus para este segmento, com a probabilidade analisada passando de $60 \%$ para $82 \%$.

As variações da estrutura da rede logística de atendimento e da adesão dos varejistas constituíram 20 situações possíveis para a configuração do modelo de CDU. Neste sentido, o cenário com cinco terminais de apoio e 100\% de adesão dos varejistas foi apresentado como uma boa alternativa para a formatação da distribuição urbana de mercadorias na região analisada. É importante frisar que, por meio da análise do coeficiente de variação dos resultados dos parâmetros econômicos e ambientais, observou-se que a estrutura da rede logística, ou seja, a quantidade de terminais de apoio e a presença dos pontos de consolidação não se figuram como elementos significativos para os objetivos do modelo de CDU. Isto porque a variação da estrutura do modelo resultou em baixa oscilação dos valores parâmetros econômicos e ambientais avaliados. Já a variação da adesão dos varejistas acarretou uma elevada mudança nestes parâmetros, indicando ser este um elemento importante no modelo proposto. Com isto, pode ser verificar que o estabelecimento de estratégias que garantam a efetiva participação dos varejistas no modelo de CDU é um aspecto fundamental para a mitigação as externalidades negativas do transporte urbano de cargas e também para a redução dos custos deste sistema de distribuição de mercadorias.

Este trabalho contribuiu com o desenvolvimento de uma proposta metodológica para a avaliação dos benefícios da implantação de um CDU fundamentando-se em critérios econômicos e ambientais, além de utilizar técnicas de preferência declarada para a definição da adesão dos varejistas ao sistema de distribuição proposto assim como subsidiar a definição dos cenários analisados. É importante que trabalhos futuros utilizem uma abordagem multicritério para a definição dos cenários de adesão dos varejistas. O desenvolvimento de heurísticas para os estudos de localização e roteirização podem melhorar a confiabilidade dos resultados das pesquisas envolvendo o tema exposto neste artigo. 


\section{Referências}

Almeida, L. M. W. (1999) Desenvolvimento de uma metodologia para análise locacional de sistemas educacionais usando modelos de interação espacial e indicadores de acessibilidade. Tese (Doutorado em Engenharia de Produção) - Pós-Graduação em Engenharia de Produção, Universidade Federal de Santa Catarina, Florianópolis.

Baldacci, R., Mingozzi, A., Roberti, R. e Calvo, R. W. (2013) An exact algorithm for the two-echelon capacitated vehicle routing problem. Operations Research, vol. 6, n. 2, pp. 298-314.

Benjelloun, A., Crainic, T.G. e Brigas, Y. (2009) Toward a taxonomy of city logistics projects. The Sixth International Conference on City Logistics, vol. 2, n. 3, pp. 6217-6228.

BHTRANS (2012) Empresa de Transporte e Trânsito de Belo Horizonte - Site Institucional. Disponível em www.bhtrans.pbh.gov.br.

Browne, M., Piotrowska, M., Woodburn, A. e Allen, J. (2007) Literature Review WM9: Part I - Urban Freigth Transport. Documento de Trabalho - University of Westminster, London.

Browne, M., Sweet, M., Woodburn, A. e Allen, J. (2005) Urban freight consolidation centers. Documento de Trabalho - University of Westminster, London.

Carrara, C. M. (2007) Uma aplicação do SIG para a localização e alocação de terminais logísticos em áreas urbanas congestionadas. Dissertação (Mestrado em Engenharia Civil) - Universidade de São Paulo, São Carlos.

Castro, N. (2013) Mensuração de externalidades do transporte de carga brasileiro. Journal of Transport Literature, vol. 7, n. 1, pp.163-181.

Chwesiuk, K., Kijewska, K. e Iwan, S. (2010) Idea of urban consolidation centres for medium-size touristics cities of Westpomeranian Region of Poland. The sixth International Conference on City Logistics. vol. 2, n. 3, pp. 6264-6273

Crainic, T. G. e Kim, K. H. (2007) Intermodal Transportation. Handbooks in Operations Research and Management Science. Amsterdam: Editora Elsevier. vol. 14. pp. 467-537.

Crainic, T. G., Ricciardi, N. e Storchi, G. (2009a) Models for evaluating and planning city logistics systems. Transportation Science, vol. 43, n. 4, pp. 432-454.

Crainic, T. G., Gendreau, M. e Potvin, J.Y. (2009b) Intelligent freight-transportation systems: assessment and the contribution of operations research. Transportation Research Part C, vol. 17, pp. 541-557.

Crainic, T. G., Ricciardi, N. e Storchi, G. (2004) Advanced freight transportation systems for congested urban areas. Transportation Research Part C, vol. 12, p. 119-137.

Dablanc, L. (2007) Goods transport in large European cities: Difficult to organize, difficult to modernize. Transportation Research Part A, vol. 41, pp. 280-285.

Dablanc, L. (2008) Urban goods movement and air quality policy and regulation issues in European cities. Journal of Environmental Law, pp. 1-2.

Dablanc, L. (2010) Freight transport, a key element of the urban economy, guidelines for practitioners. 89th Annual Meeting of Transportation Research Board. Washington DC.

Fundação João Pinheiro. (2003) Pesquisa domiciliar de origem e destino na região metropolitana de Belo Horizonte em 2001/2002. Belo Horizonte. 
GHG Protocol (2010) Especificações do Programa Brasileiro GHG Protocol: Contabilização, Quantificação e Publicação de Inventários Corporativos de Emissões de Gases de Efeito Estufa. Documento de trabalho - Fundação Getúlio Vargas e World Resources Institute, Segunda Edição.

Hensher, D. e Figliozzi, M. (2007) Behavioral insights into the modelling of freight transportation and distribution systems. Transportation Research Part B, vol. 41, p. 921-923.

Karrer, R. e Ruesch, M. (2007) Road pricing and urban freight transport - Urban freight platforms. Documento de trabalho - BESTUFS II: Best Urban Freight Solutions II.

Kroes, P. E. e Sheldon, R. J. (1988) Stated preference methods: an introduction. Journal of Transport Economics and Policy, vol. 28, n. 1, pp. 11-25.

Jepsen, M., Spoorenddonk, S. e Ropke, S. (2013) A branch-and-cut algorithm for the symmetric two-echelon capacitated vehicle routing problem. Transportation Science, vol. 47, pp. 23-37.

Martins, R. S., Lobo, D. S. e Pereira, S. M. (2005) Atributos Relevantes no Transporte de Granéis Agrícolas: Preferência Declarada pelos Embarcadores. Revista de Economia e Negócio, vol. 3, n. 2, pp. 173-192.

Minihane, E. D (2009) Bristol Consolidation Centre. Documento de Trabalho - START - Short term actions to reorganize transport of goods, Bristol.

Nemoto, T., Browne, M., Visser, J. e Castro, J. T. (2006) Intermodal transport and city logistics policies. The 4th International Conference on City Logistic, Langkaui.

PBH (2012). Prefeitura Municipal de Belo Horizonte - Site institucional. Disponível em www.pbh.gov.br.

Perboli, G., Tadei, R. e Vigo, D. (2011) The two-echelon capacitated vehicle routing problem: models and math-based heuristics. Transportation Science, vol. 45, pp. 364-380.

Quak, H. (2008) Sustainability of urban freight transport retail distribution and local regulations in cities. Thesis (Ph.D. in Management), Erasmus Research Institute of Management (ERIM), Erasmus University Rotterdam, Rotterdan.

Rooijen, T. V. e Quak, H. (2010) Local impacts of a new urban consolidation centre - the case of Binnenstadservice.NL. The Sixth International Conference on City Logistics, vol. 2, n. 3, pp. 5967-5979.

Santos, F. A., Cunha, A. S. e Mateus, F. R. (2012) Branch-and-price algorithms for the two-echelon capacitated vehicle routing problem. Optimization Letters, vol. 7, pp. 1537-1547.

Souza, O. A. (1999) Delineamento experimental em ensaios fatoriais utilizados em preferência declarada. Tese (Doutorado em Engenharia da Produção) Universidade Federal de Santa Catarina, Florianópolis.

Taniguchi, E. e Heijden, R. E. C. M. V. D. (2000) An evaluation methodology for city logistics. Transportation Reviews, vol. 20, n. 1, pp. 65-90.

Taniguchi, E., Thompson, R. G., Yamada, T. e Duin, R. V. (2001) City Logistics: Network Modelling and Intelligent Transport Systems. Elsevier Science Limited, England. 